NASA Technical Memorandum 106179

AIAA-93-2044

\title{
CFD Mixing Analysis of Axially Opposed Rows of Jets Injected Into Confined Crossflow
}

D.B. Bain and C.E. Smith

CFD Research Corporation

Huntsville, Alabama

and

J.D. Holdeman

Lewis Research Center

Cleveland, Ohio

Prepared for the

29th Joint Propulsion Conference and Exhibit

cosponsored by the AIAA, SAE, ASME, and ASEE

Monterey, California, June 28-30, 1993 


\title{
CFD MIXING ANALYSIS OF AXIALLY OPPOSED ROWS OF JETS INJECTED INTO CONFINED CROSSFLOW
}

\author{
D. B. Bain* and C. E. Smith** \\ CFD Research Corporation \\ Huntsville, Alabama \\ J. D. Holdeman ${ }^{* * *}$ \\ NASA Lewis Research Corporation \\ Cleveland, Ohio
}

\begin{abstract}
$\underline{\text { Abstract }}$
A CFD parametric study was performed to analyze axially opposed rows of jets mixing with crossflow in a rectangular duct. Isothermal analysis was conducted to determine the influence of lateral geometric arrangement on mixing. Two lateral arrangements were analyzed: 1) inline (jets' centerlines aligned with each other on top and bottom walls), and 2) staggered (jets' centerlines offset with each other on top and bottom walls). For a jet-to-mainstream mass flow ratio (MR) of 2.0, design parameters were systematically varied for jet-tomainstream momentum-flux ratios (J) between 16 and 64 and orifice spacing-to-duct height ratios $(\mathrm{S} / \mathrm{H})$ between 0.125 and 1.5 .

Comparisons were made between geometries optimized for $\mathrm{S} / \mathrm{H}$ at a specified J. Inline configurations had a unique spacing for best mixing at a specified J. In contrast, staggered configurations had two "good mixing" spacings for each $\mathrm{J}$, one corresponding to optimum inline spacing and the other corresponding to optimum non-impinging jet spacing. The inline configurations, due to their smaller orifice size at

optimum $\mathrm{S} / \mathrm{H}$, produced better initial mixing characteristics. At downstream locations (e.g. x/H of 1.5), the optimum non-impinging staggered configuration produced better mixing than the optimum inline configuration for $\mathrm{J}$ of 64 ; the opposite results were observed for $\mathrm{J}$ of 16 . Increasing $\mathrm{J}$ resulted in better mixing characteristics if each configuration was optimized with respect to orifice spacing. Mixing performance was shown to be similar to results from previous dilution jet mixing investigations $(\mathrm{MR}<0.5)$.

\section{$\underline{\text { Nomenclature }}$}

$\begin{array}{ll}\mathrm{C} & (\mathrm{S} / \mathrm{H}) \sqrt{\mathrm{J}} \quad \text { (see Eq. 1) } \\ \mathrm{C}_{\mathrm{avg}} & \mathrm{m}_{\mathrm{j}} /\left(\mathrm{m}_{\mathrm{j}}+\mathrm{m}_{\infty}\right)=\theta_{\mathrm{EB}} \\ \mathrm{H} & \text { Duct Height } \\ \mathrm{J} & \text { Momentum-Flux Ratio }\left(\rho_{\mathrm{j}} \mathrm{V}_{\mathrm{j}}^{2}\right) /\left(\rho_{\infty} \mathrm{U}_{\infty}^{2}\right) \\ \mathrm{L} & \text { Orifice Length (long dimension) } \\ \mathrm{L} / \mathrm{W} & \text { Orifice Aspect Ratio (SAR in previous reports) } \\ \mathrm{m}_{\mathrm{j}} & \text { Mass Flow of Jets } \\ \mathrm{m}_{\infty} & \text { Mass Flow of Mainstream Flow } \\ \mathrm{MR} & \text { Mass Flow Ratio } \mathrm{m}_{\mathrm{j}} / \mathrm{m}_{\infty} \\ \mathrm{P} & \text { Pressure }\left(\mathrm{N} / \mathrm{m}^{2}\right) \\ \mathrm{S} & \text { Orifice Spacing }\end{array}$

* $\quad$ Project Engineer, Member AIAA

* Vice President/Engineering, Member AIAA

*** Senior Research Engineer, Associate Fellow AIAA
\end{abstract}

Copyright (C) 1993 by the American Institute of Aeronautics and Astronautics, Inc. No copyright is asserted in the United States under Title 17, U.S. code. The U. S. Government has a royalty-free license to exercise all rights under the copyright claimed herein for Govermental purposes. All other rights are reserved by the copyright owner. 


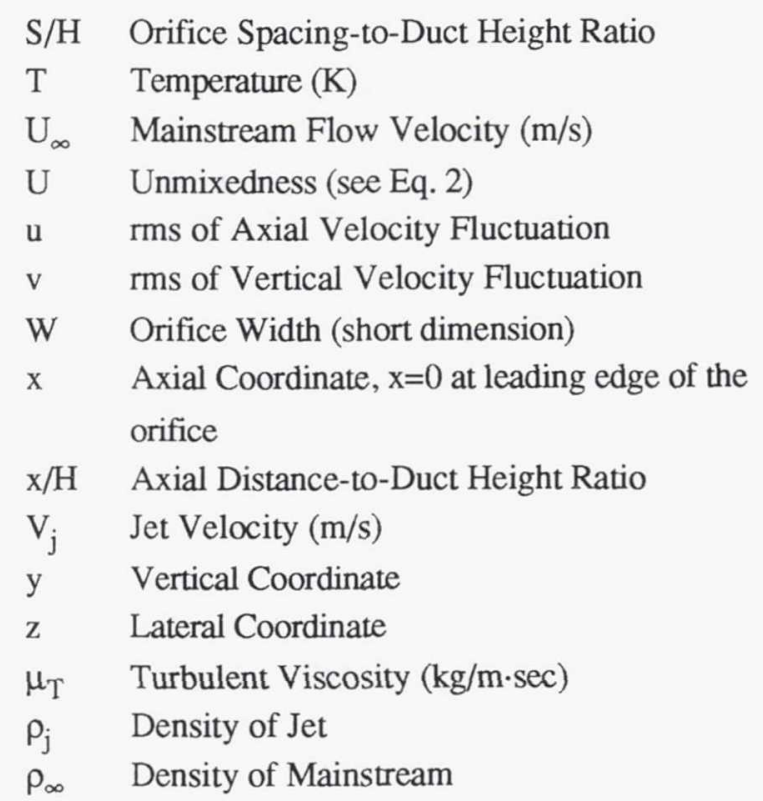

\section{Introduction}

The technology demonstration of low $\mathrm{NO}_{\mathrm{x}}$ combustors applicable to commercial aircraft is a subject of ongoing research. ${ }^{1}$ One combustor concept currently being evaluated both numerically and experimentally is the Rich-burn/Quick-mix/Lean-burn (RQL) combustor. The RQL combustor utilizes staged burning. ${ }^{2}$ In this concept, the rich-burn zone is designed to operate at equivalence ratios greater than 1 . The combustion products from the rich-burn section enter the quick mix section where mixing takes place with bypass air. The combustion process is then completed in the lean-burn region.

A key design technology required for successful demonstration of the RQL concept is a method of rapidly mixing bypass air with rich-burn gases to suppress the formation of harmful emissions. Recent studies have been performed that focus on identifying improved mixing concepts. ${ }^{3-13}$ The current investigation focuses on jet mixing in rectangular crosssectional ducts.

\section{Background}

The mixing of jets in a confined crossflow has been important in gas turbine combustion applications for many years. Perhaps foremost in importance is the jet mixing that occurs in the combustor dilution zone. In conventional annular gas turbine combustors, the dilution zone is the aft zone in which air dilutes combustion products before entering the turbine. The dilution jets should effectively penetrate and mix with combustion gases, thereby establishing a temperature profile acceptable to the turbine. The typical range of jet-to-mainstream mass flow ratio (MR) is 0.25 to 0.50 .

RQL jet mixing applications offer some sharp contrasts to conventional dilution zone mixing. First, the mass flow ratio is approximately 2.0. Such a large MR results in larger orifices, potentially creating jet blockage effects that can substantially affect mixing. Because round orifices may not be practical due to blockage and structural concerns, slots may be needed. Second, low pollutant levels are the drivers for "good" mixing in RQL applications, in contrast to temperature profile and "hot spots" for dilution zone applications.

Significant research has been performed for dilution zone mixing. ${ }^{14}$ This research has identified two design variables that control jet penetration and mixing characteristics: 1) jet-to-mainstream momentum-flux ratio (J) and 2) orifice spacing-to-duct height ratio $(\mathrm{S} / \mathrm{H})$. Single-sided (from one wall only) injection was extensively studied while two-sided (from top and bottom walls) injection was studied to a lesser extent. Optimum mixing relationships were determined to be a function of $(\mathrm{S} / \mathrm{H}) \sqrt{\mathrm{J}}$ for the range of conditions tested and analyzed.

$$
\mathrm{C}=(\mathrm{S} / \mathrm{H}) \sqrt{\mathrm{J}}
$$

For one-sided injection, optimum mixing was obtained when $\mathrm{C}$ was about 2.5 . 
Two-sided injection with an inline lateral arrangement was shown to be similar to one-sided injection if the duct was considered sliced in half, yielding a constant of proportionality that is one-half of the corresponding value for one-sided injection. Thus a $\mathrm{C}$ of 1.25 would be expected for optimum mixing of opposed rows of jets with centerlines inline.

For two-sided injection with a staggered lateral arrangement, very little data, either experimentally or numerically, have been generated. Holdeman ${ }^{14}$ has suggested staggered holes produce optimum mixing if the jets penetrate past each other. He determined (from the few tests conducted) that best mixing was obtained when alternate jets for optimum one-sided injection were moved to the opposite wall. Thus the correlation constant would be expected to be 5.0 for opposed rows of jets with centerlines staggered.

A basic question often arises concerning which lateral arrangement produces superior mixing: inline or staggered. This fundamental question has never truly been answered. Indeed, even combustor designers differ in their opinion, as evidenced by conventional dilution zones with both types of Iateral alignments. As an added complication in this RQL application, past results may not be directly applicable due to the mass flow ratio $(0.50$ for conventional dilution zone vs 2.0 for RQL). This study sought to address the lateral arrangement issue by a systematic computational investigation. A complete description of the cases studied and their results are discussed below.

\section{3. $\underline{\text { CFD Code }}$}

The approach in this study was to perform 3-D numerical calculations on a generic geometry section. The CFD code named REFLEQS ${ }^{15}$ was used to perform the computations. The basic capabilities/methodologies in REFLEQS include:
1. Solution of two- and three-dimensional, timeaccurate or steady-state Navier-Stokes equations for incompressible and compressible flows;

2. Cartesian, polar, and non-orthogonal body-fitted coordinates;

3. Porosity-resistivity techniques for flows with internal blockages;

4. Fully implicit and strongly conservative formulation;

5. Three differencing schemes: upwind, hybrid, and central differencing with damping terms;

6. Standard, extended, and low Reynolds number k$\varepsilon$ turbulence models, and the multiple-scale turbulence model of Chen;

7. Instantaneous, one-step and two-step combustion models;

8. Modified form of Stone's strongly implicit solver; and

9. Pressure-based solution algorithms including SIMPLE and a variant of SIMPLEC.

\section{Details of Numerical Calculations}

A schematic of the numerical model is shown in Figure 1. The height of the mixing section was 4 inches $(0.1016 \mathrm{~m}$.). The mainstream flow entered the calculation domain one duct height upstream $(x / H$ of -1.0) of the leading edge of the orifices, and continued downstream to $\mathrm{x} / \mathrm{H}$ of 7.0 . The model consisted of jet injection from top and bottom walls into mainstream flow. All of the orifices were straight slots with an aspect ratio of $4: 1$, with the long dimension of the slot in the direction of the mainstream flow.

Two orifice arrangements were modeled: staggered and inline. For the staggered cases, the lateral calculation domain extended from midplane to midplane between top and bottom jet centerlines, and modeled one jet on the top wall and one jet on the bottom wall. Periodic boundary conditions were imposed along the lateral boundaries. For the inline cases, the lateral domain extended from midplane to midplane between the jets' centerlines. Again periodic lateral boundary conditions 
were imposed. It should be noted that the staggered configurations consisted of twice the lateral domain of the inline configurations.

Six parametrics consisting of 44 cases were analyzed as shown in Table 1. The case sequence for each parametric consisted of fixing $\mathrm{J}$ (at 16,36 , or 64 ) and lateral arrangement (inline or staggered), and then parametrically changing $\mathrm{S} / \mathrm{H}$ to optimize mixing. For each parametric, the slot geometry producing optimum mixedness is shown in Figure 2.

The flow conditions of the mainstream and jets were

$$
\begin{aligned}
& \text { Mainstream } \quad \underline{\text { Jets }} \\
& \mathrm{U}_{\infty}=10 \mathrm{~m} / \mathrm{s} \quad \mathrm{V}_{\mathrm{j}}=40 \mathrm{~m} / \mathrm{s}^{*} \\
& 60 \mathrm{~m} / \mathrm{s}^{*} \\
& \mathrm{~T}_{\infty}=300 \mathrm{~K} \quad \mathrm{~T}_{\mathrm{j}}=300 \mathrm{~K} \\
& \mathrm{u} / \mathrm{U}_{\infty}=0.20 \quad \mathrm{v} / \mathrm{V}_{\mathrm{j}}=0.20 \\
& \mu_{\mathrm{T}}=\begin{array}{l}
1 \times 10^{-2} \\
\mathrm{~kg} / \mathrm{m} \cdot \mathrm{sec}
\end{array} \quad \mu_{\mathrm{T}}=\begin{array}{l}
1 \times 10^{-2} \\
\mathrm{~kg} / \mathrm{m} \cdot \mathrm{sec}
\end{array} \\
& \mathrm{P}=1 \times 10^{5} \mathrm{~N} / \mathrm{m}^{2} \\
& \mathrm{~J}=16,36,64 \\
& \mathrm{~m}_{\mathrm{j}} / \mathrm{m}_{\infty}=2.0
\end{aligned}
$$

* $\quad \mathrm{V}_{\mathrm{j}}$ varies according to specified $\mathrm{J}$.

The turbulent length scales of the jets were varied to maintain a constant inlet turbulent viscosity.

\section{Grids}

A typical staggered case consisted of 80,000 cells, 64 cells in the axial (x) direction, 28 cells in the vertical (y) direction, and 44 cells in the lateral (z) direction. The slots were composed of 144 ( $24 \times 6)$ evenly distributed cells. The grid upstream and downstream of the slot region was expanded/contracted so that each cell adjacent to the slot region matched the cell size in the slot region. The cells in the vertical direction were all of uniform size. Note that the grid size for the inline cases were typically half the size for the staggered cases.

In earlier works ${ }^{8}$, a much finer grid $(\approx 145,000$ cells $)$ was used in the numerical calculations. Since that paper, a grid density study has been performed and it was determined that such fine grids are not needed for engineering calculations. Thus, the number of cells was reduced for computational efficiency in this study.

\section{$\underline{\text { Numerics }}$}

The following conservation equations were solved: $u$ momentum, $\mathrm{v}$ momentum, w momentum, mass (pressure correction), turbulent kinetic energy (k), and turbulent energy dissipation $(\varepsilon)$. The convective fluxes were calculated using upwind differencing, and the diffusive fluxes were calculated using central differencing. The standard $\mathrm{k}-\varepsilon$ turbulence model was employed and conventional wall functions were used.

\section{Convergence}

All error residuals were reduced at least 6 orders of magnitude, and continuity was conserved in each axial plane to the fifth decimal. Convergence was relatively smooth requiring about 600 iterations. A converged solution required approximately $4.0 \mathrm{CPU}$ hours on a CRAY-YMP computer.

\section{Data Postprocessing}

In order to quantify the mixing effectiveness, the areaaveraged spatial concentration variance of jet flow was calculated in each axial plane. The use of area-averaged quantities, rather than mass-averaged quantities, was chosen to be consistent with concurrent experimental measurements and allow one-to-one comparison. The area-averaged unmixedness $(U)$ is defined ${ }^{16}$ as

$$
\mathrm{U}=\mathrm{C}_{\mathrm{var}} /\left[\mathrm{C}_{\mathrm{avg}}\left(1-\mathrm{C}_{\mathrm{avg}}\right)\right]
$$


where

$$
\begin{array}{ll}
\mathrm{C}_{\text {var }} & =\left(1 / \mathrm{A}_{\text {TOT }}\right) \sum_{\mathrm{i}} \mathrm{A}_{\mathrm{i}}\left(\mathrm{C}_{\mathrm{i}}-\mathrm{C}_{\mathrm{avg}}\right)^{2} \\
\mathrm{~A}_{\mathrm{TOT}} & =\text { total flow area in each axial plane } \\
\mathrm{A}_{\mathrm{i}} & =\text { flow area of cell } i \\
\mathrm{C}_{\mathrm{i}} & =\text { jet mass fraction in cell } i \\
\mathrm{C}_{\text {avg }} & =\mathrm{m}_{\mathrm{j}} /\left(\mathrm{m}_{\mathrm{j}}+\mathrm{m}_{\infty}\right)=\theta_{\mathrm{EB}}
\end{array}
$$

For this study, $\mathrm{C}_{\mathrm{avg}}$ is 0.667.

The use of $\mathrm{C}_{\mathrm{avg}}$ in determining $U$ is only correct downstream of the slots' trailing edge. Upstream of the slots' trailing edge, the injection of jet mass flow makes the use of $\mathrm{C}_{\text {avg }}$ incorrect. Therefore, the unmixedness values shown plotted in this paper always begin one computational cell aft of the slots' trailing edge.

\section{Results and Discussion}

Figure 3 displays the results for the inline and staggered configurations for a $\mathrm{J}$ of 16,36 , and 64 . The optimum $\mathrm{S} / \mathrm{H}$ ratio for each parametric is identified by the boldest curve. Discussion of these results is presented below.

\section{Effect of S/H on Jet Penetration}

A qualitative view of how $\mathrm{S} / \mathrm{H}$ affects jet penetration and corresponding mixing levels is shown in Figures 4, 5 , and 6 . These figures show the jet mass fraction concentrations for inline slots at $J$ of 16, 36, and 64 . The views presented are lateral slices taken through the slot centerline. S/H variations are presented to illustrate the effect of $\mathrm{S} / \mathrm{H}$ on jet penetration. For discussion, the cases for $\mathrm{J}$ of 36 (i.e. Figure 5) present the essential features of jet penetration into crossflow. At the smaller $\mathrm{S} / \mathrm{H}$, the jets are underpenetrated, allowing the approach flow to pass through the center of the duct. As $\mathrm{S} / \mathrm{H}$ increases, the jets penetrate farther into the duct, beginning to pinch off the approach flow along the duct centerline. At the largest $\mathrm{S} / \mathrm{H}$, the jets have clearly over-penetrated, blocking off most of the approach flow in the center of the duct and forcing more of the approach flow to go between the jets. S/H of 0.375 gives the optimum penetration which agrees well with the optimum $\mathrm{S} / \mathrm{H}$ in terms of unmixedness (as shown in Figure 3). In general terms, inline jets that penetrate to about $1 / 4$ duct height produce optimum mixing.

Similar lateral slices showing jet penetration for staggered slots at $J$ of 16,36 , and 64 are shown in Figures 7, 8, and 9. The lateral planes in these figures are through the centerline of the top jets, and the corresponding plane through the bottom jet would be the mirror image of that shown. In contrast to optimum inline configurations, optimum staggered jets penetrate completely across the duct and do not collide with each other. As will be discussed later, another "good mixing" orifice spacing is obtained for staggered configurations if staggered jets are configured at optimum inline spacing. In this case, the staggered jets penetrate to $1 / 4$ duct height, just like the optimum inline jets. To differenciate between these two "good mixing" modes for staggered jets, the term "nonimpinging staggered configuration" will refer to jets that penetrate across the duct.

\section{Effect of J}

The effect of $\mathrm{J}$ on unmixedness is shown in Figure 10 for inline slots, and in Figure 11 for nonimpinging staggered slots. Each curve represents the optimum $\mathrm{S} / \mathrm{H}$ for a specified J. Both lateral arrangements, staggered and inline, exhibited an initial mixing advantage gained by increasing $\mathrm{J}$ from 16 to 64 . The improved initial mixing is caused by the slots being geometrically smaller as $\mathrm{J}$ increases from 16 to 64. Downstream mixing (i.e. $\mathrm{x} / \mathrm{H}$ of 1.5 ) is seen to be similar for inline geometry as $\mathrm{J}$ varies, but substantial improvement is seen when $\mathrm{J}$ is increased for nonimpinging staggered configurations.

The jet mass fraction concentrations for inline and staggered slots are shown in Figure 12. The location of the axial section is $x / H$ of 0.75 . Using the criteria of 
better mixing being indicated by fewer concentration levels, the cases for $\mathrm{J}$ of 64 are more thoroughly mixed than the $\mathrm{J}$ cases of 16 or 36 . The enhancement in mixing by an increase in $\mathrm{J}$ is not unexpected due to a higher pressure drop experienced as $\mathrm{J}$ is increased.

\section{Effect of Lateral Arrangement on Mixing}

The effect of lateral arrangement on unmixedness is shown in Figures 13, 14, and 15 for $\mathrm{J}$ of 16, 36, and 64 , respectively. Only the curves corresponding to optimum $\mathrm{S} / \mathrm{H}$ are presented. In each figure, it can be seen that the inline slots have better initial mixing. This is due to the inline orifices being substantially smaller than staggered orifices. At locations farther downstream (i.e. $\mathrm{x} / \mathrm{H}$ of 1.5 ), inline is better than staggered at $\mathrm{J}$ of 16 , but inline is worse than staggered at $J$ of 64 . Indeed, the best mixing case of all cases studied is the staggered case shown in Figure 15 for $\mathrm{J}$ of 64. The unmixedness values for the best mixing case was 0.02 at $\mathrm{x} / \mathrm{H}$ of 1.5 .

A more qualitative comparison of mixing illustrating the effect of lateral arrangement is presented in Figures 16, 17, and 18. These figures present jet mass color concentration maps for the optimum inline and non-impinging staggered configurations at three momentum-flux ratios ( $\mathrm{J}$ of 16,36 , and 64 , respectively). The multiple cycles shown in these figures were generated graphically to maintain the same cross-sectional area for each case. It can be seen that the inline slots produce better initial mixing than the staggered slots at $\mathrm{x} / \mathrm{H}$ of 0.75 .

For completeness, a single-sided injection case was examined to determine the impact of two-sided vs onesided injection. Figure 19 shows the jet mass fraction concentrations for the two-sided and single-sided injection cases at their optimum $\mathrm{S} / \mathrm{H}$. It would be expected (based on previous dilution jet studies ${ }^{14}$ ) that optimum staggered two-sided injection would have:
1) an $\mathrm{S} / \mathrm{H}$ that is four times the $\mathrm{S} / \mathrm{H}$ of inline twosided injection; and

2) two times the $\mathrm{S} / \mathrm{H}$ of single-sided injection.

Numerically, the ratios were found to be 2.3 and 1.4, respectively. Based on previous research, optimum mixing was reached if the jets penetrated one-quarter of the way into the duct for inline slots, penetrated past each other for staggered slots, and penetrated to the duct centerline for single-sided injection. Figure 19 illustrates that the numerical results in this study coincide well with the previous research. In terms of unmixedness, the two-sided injection cases show a significant advantage over the single-sided cases, as seen in Figure 20.

When experimental mixing tests are performed, only a limited number of orifice configurations can be tested. Typically, inline arrangements are first tested, followed by a lateral movement of one wall to produce staggered arrangements. If an inline arrangement at a given $\mathrm{J}$ is optimized (in terms of $\mathrm{S} / \mathrm{H}$ ), the corresponding staggered case obtained by laterally moving one wall will produce nearly identical mixing (see Figure 21). The converse is not true; i.e., if a non-impinging staggered arrangement at a given $\mathrm{J}$ is optimized, the corresponding inline case will produce inferior mixing (see Figure 21).

Figures 22 and 23 show the unmixedness comparisons of inline and non-impinging staggered configurations at the same $\mathrm{S} / \mathrm{H}$. In Figure 22 it is evident that running the inline configuration at optimum non-impinging staggered spacing $(\mathrm{S} / \mathrm{H}$ of 0.85 ) produces poorer mixing characteristics than the optimum staggered case. In contrast, there is no difference seen (see Figure 23) between inline and staggered results at the optimum inline spacing $(\mathrm{S} / \mathrm{H}$ of 0.375). Staggered configurations thus have two minimum values of unmixedness, as shown in Figure 24 for $\mathrm{J}$ of 36 . One minimum value corresponds to the optimum $\mathrm{S} / \mathrm{H}$ arrangement for non-impinging jets $(\mathrm{S} / \mathrm{H}$ of 0.85$)$, and the other minimum value 
corresponds to jets not being able to penetrate by each other ( $\mathrm{S} / \mathrm{H}$ of 0.375$)$. Inline configurations have only a unique minimum unmixedness value (at $\mathrm{S} / \mathrm{H}$ of 0.375 ) as shown in Figure 25.

Comparison to Empirical Calculations for Optimum Mixing

Shown in Table 2 are the empirically and numerically determined constants for optimum mixing for the cases studied. For the inline cases, the numerical constant is about $75 \%$ higher than the empirical constant. Most of this difference may be attributed to the effect of mass flow ratio, since the empirical constants were based on experiments with mass flow ratios less than 0.50 , while the numerical constants were determined with a mass flow ratio of 2.0. (In other CFD studies not reported here, the numerical constant was only $30 \%$ higher than the empirical constant for a mass flow ratio of 0.5 ). Note that the jet blockage (at the wall) was about 33\% for all $\mathrm{J}$ values. The constant blockage for all $\mathrm{J}$ values is expected due to geometry considerations if blockage is not important in the mixing process.

For the staggered cases, the numerical constants vary from $25 \%$ low for J of 16 to $36 \%$ high for J of 64 . This agreement is considered adequate from an engineering design viewpoint, but there is probably a secondary effect (e.g. grid density, inlet turbulence boundary conditions, etc.) that is causing the disagreement.

\section{Conclusions}

A CFD parametric mixing study was performed on axially opposed rows of staggered and inline jets injected into confined rectangular crossflow. The analysis was performed at jet-to-mainstream momentum-flux ratios (J) of 16,36 , and 64 , orifice spacing-to-duct height ratios $(\mathrm{S} / \mathrm{H})$ of 0.125 to 1.5 , and a jet-to-mainstream mass flow ratio (MR) of 2.0. Based on the numerical results, the following conclusions can be drawn:
1. Inline configurations have better initial mixing than non-impinging staggered configurations at their respective optimum $\mathrm{S} / \mathrm{H}$.

2. In terms of overall downstream mixing, (i.e. at $\mathrm{x} / \mathrm{H}$ of 1.5 ), the optimum inline configuration is better than the optimum staggered configuration for $\mathrm{J}$ of 16 , but the opposite is true for $\mathrm{J}$ of 64 .

3. Increasing $\mathrm{J}$ improves initial mixing at optimum $\mathrm{S} / \mathrm{H}$. Increasing $\mathrm{J}$ improves downstream mixing (i.e. $\mathrm{x} / \mathrm{H}$ of 1.5 ) for staggered configurations, but has neglible effect for inline configurations.

4. Mixing performance is similar to results from previous dilution jet mixing investigations with jet-to-mainstream mass flow ratios less than 0.50 .

\section{Acknowledgement}

This work was supported by NASA Contract NAS325967, and NAS computer time was provided by NASA Lewis Research Center. Valuable discussions and assistance were provided by Mr. Milind Talpallikar. Our thanks are also extended to Ms. Kathy W. Rhoades for preparing this typescript.

\section{References}

1. R. J. Shaw, "Engine Technology Challenges for a 21st Century High Speed Civil Transport," AIAA Tenth International Symposium on Air Breathing Engines, September 1-6, 1991 (Also NASA TM 104363).

2. S. A. Mosier and R. M. Pierce, "Advanced Combustion Systems for Stationary Gas Turbine Engines," Vol. I, EPA Contract 68-02-2136, 1980.

3. C. E. Smith, "Mixing Characteristics of Dilution Jets in Small Gas Turbine Combustors," AIAA 90-2728, 1990.

4. C. E. Smith, M. V. Talpallikar, and J. D. Holdeman, "A CFD Study of Jet Mixing in 
Reduced Flow Areas for Lower Combustor Emissions," AIAA 91-2460, June, 1991 (Also NASA TM 104411).

5. A. Vranos, D. S. Liscinsky, B. True, and J. D. Holdeman, "Experimental Study of Cross-Stream Mixing in a Cylindrical Duct," AIAA 91-2459, June, 1991 (Also NASA TM 105180).

6. M. V. Talpallikar, C. E. Smith, M. C. Lai, and J. D. Holdeman, "CFD Analysis of Jet Mixing in Low $\mathrm{NO}_{\mathrm{x}}$ Flametube Combustors," ASME Paper 91-GT-217, Vol. 114, pp. 416-424, ASME Transactions, Journal of Engineering for Gas Turbines and Power, 1992 (Also NASA TM 104466).

7. M. S. Hatch, W. A. Sowa, G. S. Samuelsen, and J.D. Holdeman, "Jet Mixing Into a Heated Cross Flow in a Cylindrical Duct: Influence of Geometry and Flow Variations," AIAA 92-0773, January 1992 (Also NASA TM 105390).

8. D. B. Bain, C. E. Smith, and J. D. Holdeman, "CFD Mixing Analysis of Jets Injected from Straight and Slanted Slots into Confined Crossflow in Rectangular Ducts," AIAA 923087, Nashville, TN, July 6-8, 1992 (Also NASA TM 105699)

9. D. S. Liscinsky, B. True, A. Vranos, and J. D. Holdeman, "Experimental Study of Cross-Stream Mixing in a Rectangular Duct," AIAA 92-3090, Nashville, TN, July 6-8, 1992 (Also NASA TM 106194).

10. V. L. Oechsle, H. C. Mongia, and J. D. Holdeman, "A Parametric Numerical Study of Mixing in a Cylindrical Duct," AIAA 92-3088, Nashville, TN, July 6-8, 1992 (Also NASA TM 105695).

11. G. Zhu and M.-C. Lai, "A Parametric Study of Penetration and Mixing of Radial Jets in NeckedDown Cylindrical Crossflow," AIAA 92-3091, Nashville, TN, July 6-8, 1992.

12. J. T. Kroll, W. A. Sowa, G. S. Samuelsen, and J. D. Holdeman, "Optimization of Circular Orifice Jets Mixing into a Heated Crossflow in a
Cylindricxal Duct," AIAA 93-0249, Reno, Nevada, January 11-14, 1993.

13. D. S. Liscinsky, A. Vranos, and R. P. Lohman, "Experimental Study of Crossflow Mixing in Cylindrical and Rectangular Ducts," NASA CR 187141, March 1993.

14. J. D. Holdeman, "Mixing of Multiple Jets with a Confined Subsonic Crossflow," AIAA 91-2458, 1991 (Also NASA TM 104412).

15. A. J. Przekwas, S. D. Habchi, H. Q. Yang, R. K. Avva, M. V. Talpallikar, and A. Krishnan, "REFLEQS-3D: A Computer Program for Turbulent Flows With and Without Chemical Reaction, Volume 1: User's Manual," CFDRC Report GR-89-4, January 1990.

16. P. V. Danckwertz, "The Definition and Measurement of Some Characteristics of Mixtures," Appl. Sci. Res., Sec. A, Vol. 3, pp. 279-296, 1952. 


\begin{tabular}{|c|c|c|c|c|c|c|c|c|}
\hline Parametric & Case & Configuration & $\frac{\text { Slot Aspect }}{\underline{\text { Ratio }}}$ & $\begin{array}{c}\text { Momentum } \\
\text { Flux Ratio (J) }\end{array}$ & $\frac{\text { Mass Flow }}{\text { Ratio (MR) }}$ & $\underline{\mathrm{S} / \mathrm{H}}$ & $\begin{array}{l}\text { Trailing } \\
\text { Edge } x / H\end{array}$ & $\frac{\begin{array}{c}\text { Jet } \\
\text { Blockage a }\end{array}}{\text { Wall }}$ \\
\hline \multirow[t]{11}{*}{ Parametric 1} & Case 1 & Inline & $4: 1$ & 36 & 2.0 & 0.125 & 0.29 & $57.7 \%$ \\
\hline & Case 2 & & & & & 0.20 & 0.36 & 45.6 \\
\hline & Case 3 & & & & & 0.228 & 0.39 & 42.8 \\
\hline & Case 4 & & & & & 0.25 & 0.41 & 40.8 \\
\hline & Case 5 & & & & & 0.275 & 0.43 & 38.9 \\
\hline & Case 6 & & & & & 0.325 & 0.47 & 35.8 \\
\hline & Case 7 & & & & & 0.375 & 0.50 & 33.3 \\
\hline & Case 8 & & & & & 0.425 & 0.53 & 31.3 \\
\hline & Case 9 & & & & & 0.50 & 0.58 & 28.9 \\
\hline & Case 10 & & & & & 0.75 & 0.71 & 23.6 \\
\hline & Case 11 & 1 & $Y$ & $V$ & $Y$ & 0.85 & 0.75 & 22.1 \\
\hline \multirow[t]{6}{*}{ Parametric 2} & Case 12 & Staggered & $4: 1$ & 36 & 2.0 & 0.375 & 0.50 & 33.3 \\
\hline & Case 13 & & & & 1 & 0.75 & 0.71 & 23.6 \\
\hline & Case 14 & & & & & 0.85 & 0.75 & 22.1 \\
\hline & Case 15 & & & & & 1.0 & 0.81 & 20.4 \\
\hline & Case 16 & & & & & 1.25 & 0.91 & 18.3 \\
\hline & Case 17 & $\nabla$ & $\downarrow$ & $\downarrow$ & $\downarrow$ & 1.50 & 1.00 & 16.7 \\
\hline \multirow[t]{7}{*}{ Parametric 3} & Case 18 & Inline & $4: 1$ & 16 & 2.0 & 0.325 & 0.57 & 43.8 \\
\hline & Case 19 & & & 1 & 1 & 0.375 & 0.61 & 40.8 \\
\hline & Case 20 & & & & & 0.425 & 0.65 & 38.4 \\
\hline & Case 21 & & & & & 0.50 & 0.70 & 35.4 \\
\hline & Case 22 & & & & & 0.55 & 0.74 & 33.7 \\
\hline & Case 23 & & & & & 0.60 & 0.77 & 32.3 \\
\hline & Case 24 & 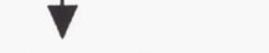 & 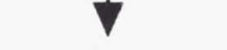 & $\checkmark$ & 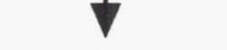 & 1.00 & 1.00 & 25.0 \\
\hline \multirow[t]{6}{*}{ Parametric 4} & Case 25 & Staggered & $4: 1$ & 16 & 2.0 & 0.50 & 0.70 & 35.4 \\
\hline & Case 26 & & & & & 0.85 & 0.92 & 27.1 \\
\hline & Case 27 & & & & & 1.0 & 1.0 & 25.0 \\
\hline & Case 28 & & & & & 1.25 & 1.12 & 22.4 \\
\hline & Case 29 & & & & & 1.30 & 1.14 & 21.9 \\
\hline & Case 30 & & $\nabla$ & $\checkmark$ & $\sqrt{ }$ & 1.50 & 1.22 & 20.4 \\
\hline \multirow[t]{8}{*}{ Parametric 5} & Case 31 & Inline & $4: 1$ & 64 & 2.0 & 0.125 & 0.25 & 50.0 \\
\hline & Case 32 & & 1 & 1 & 1 & 0.20 & 0.32 & 39.5 \\
\hline & Case 33 & & & & & 0.25 & 0.35 & 35.4 \\
\hline & Case 34 & & & & & 0.275 & 0.37 & 33.7 \\
\hline & Case 35 & & & & & 0.285 & 0.38 & 33.1 \\
\hline & Case 36 & & & & & 0.30 & 0.39 & 32.3 \\
\hline & Case 37 & & & & & 0.325 & 0.40 & 31.0 \\
\hline & Case 38 & V & $\sqrt{ }$ & $\nabla$ & $\sqrt{ }$ & 0.85 & 0.65 & 19.2 \\
\hline \multirow[t]{6}{*}{ Parametric 6} & Case 39 & Staggered & $4: 1$ & 64 & 2.0 & 0.285 & 0.38 & 33.1 \\
\hline & Case 40 & & 1 & 1 & 1 & 0.50 & 0.50 & 25.0 \\
\hline & Case 41 & & & & & 0.65 & 0.57 & 21.9 \\
\hline & Case 42 & & & & & 0.75 & 0.61 & 20.4 \\
\hline & Case 43 & & 7 & 7 & $\downarrow$ & 0.85 & 0.65 & 19.2 \\
\hline & Case 44 & $\nabla$ & $\mathbf{V}$ & $\mathbf{v}$ & $\mathbf{v}$ & 1.00 & 0.71 & 17.7 \\
\hline
\end{tabular}

Bold font represents optimum mixing configuration. 


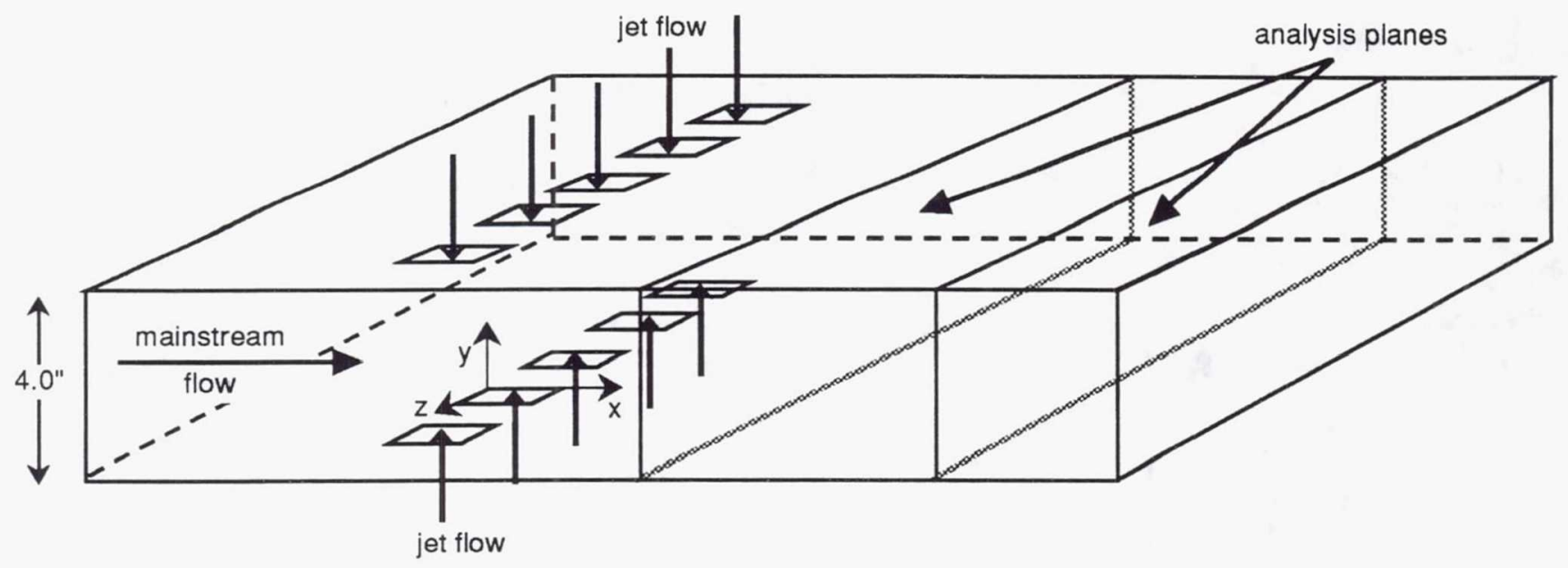

Figure 1. Schematic of Numerical Mixing Model

$\underline{\text { Inline }}$
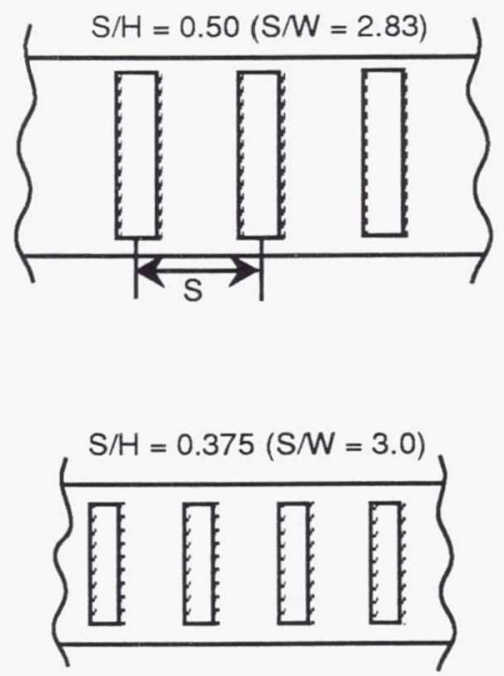

$\mathrm{J}=\mathbf{3 6}$

$J=64$
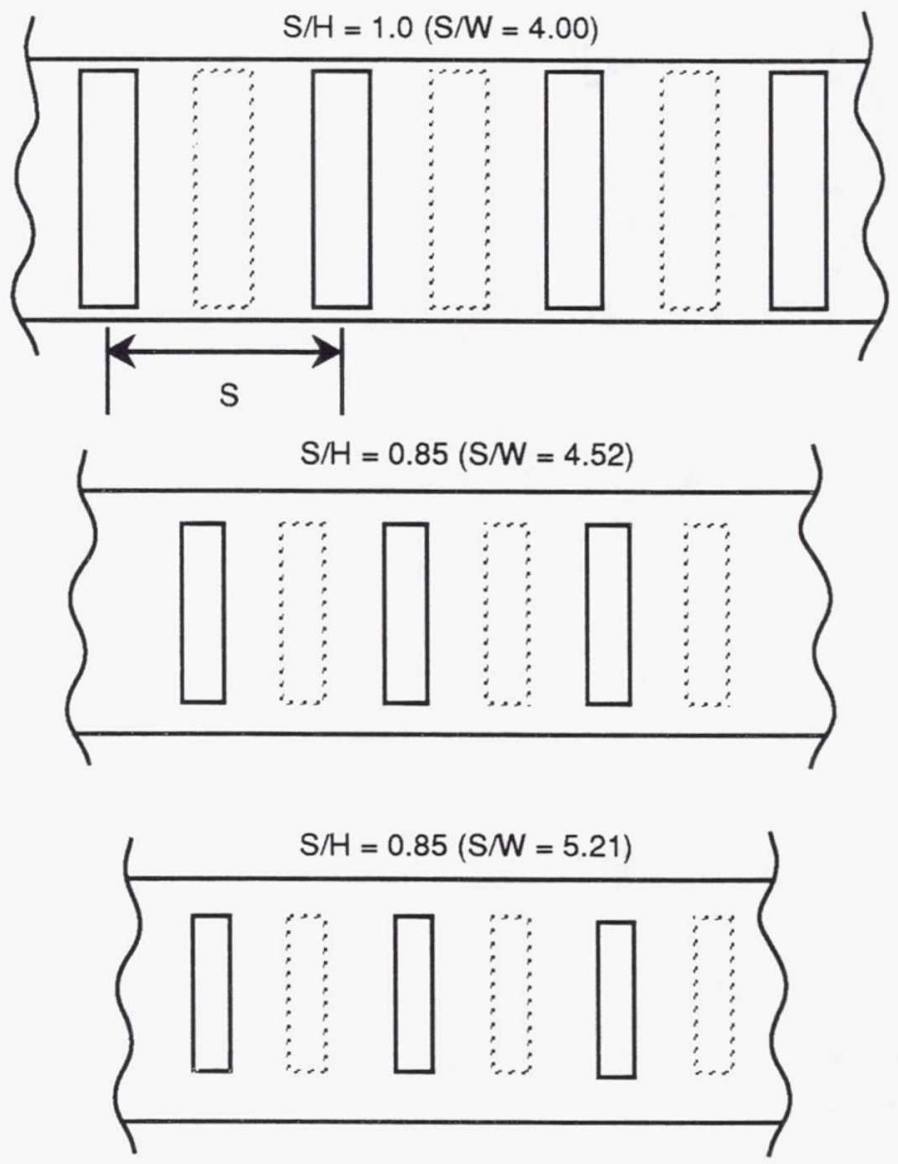

Solid Orifice: Top Wall

Dashed Orifice: Bottom Wall

Figure 2. Slot Configurations At Optimum S/H 
INLINE
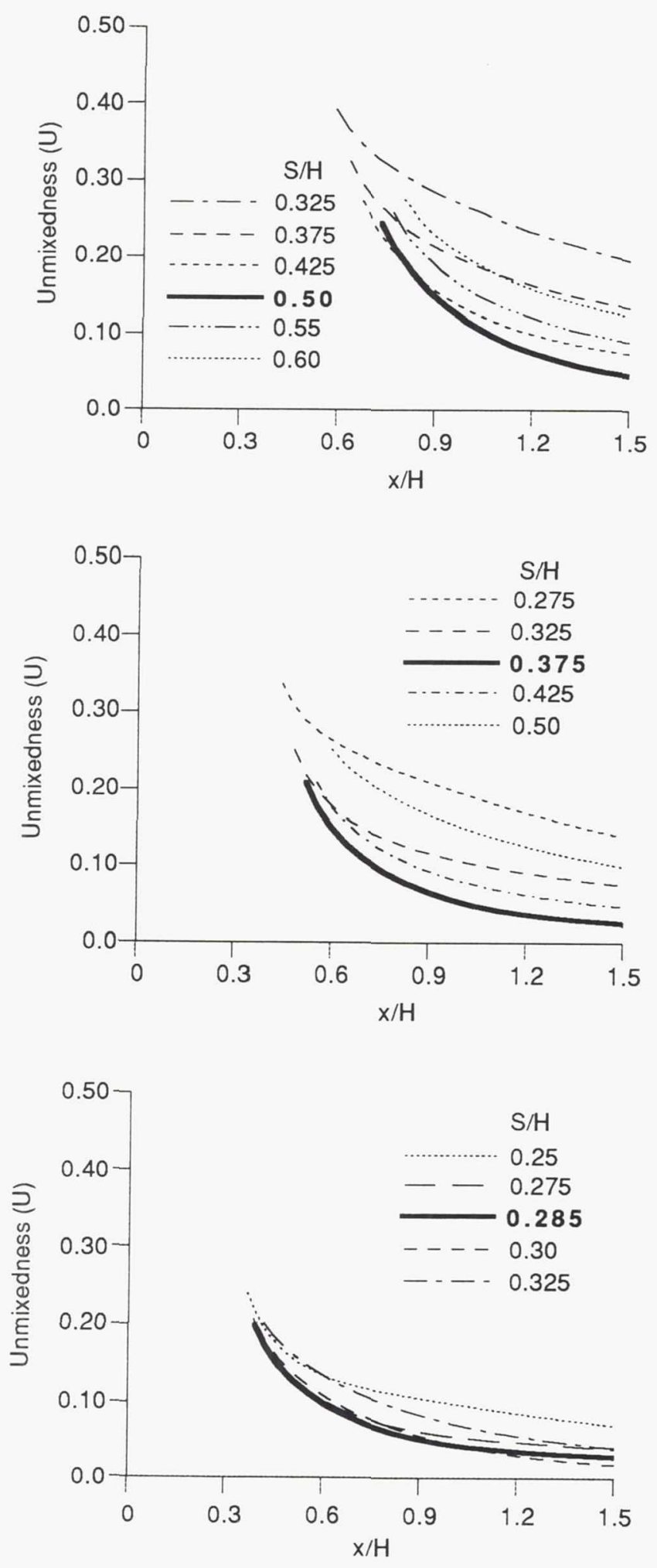

STAGGERED
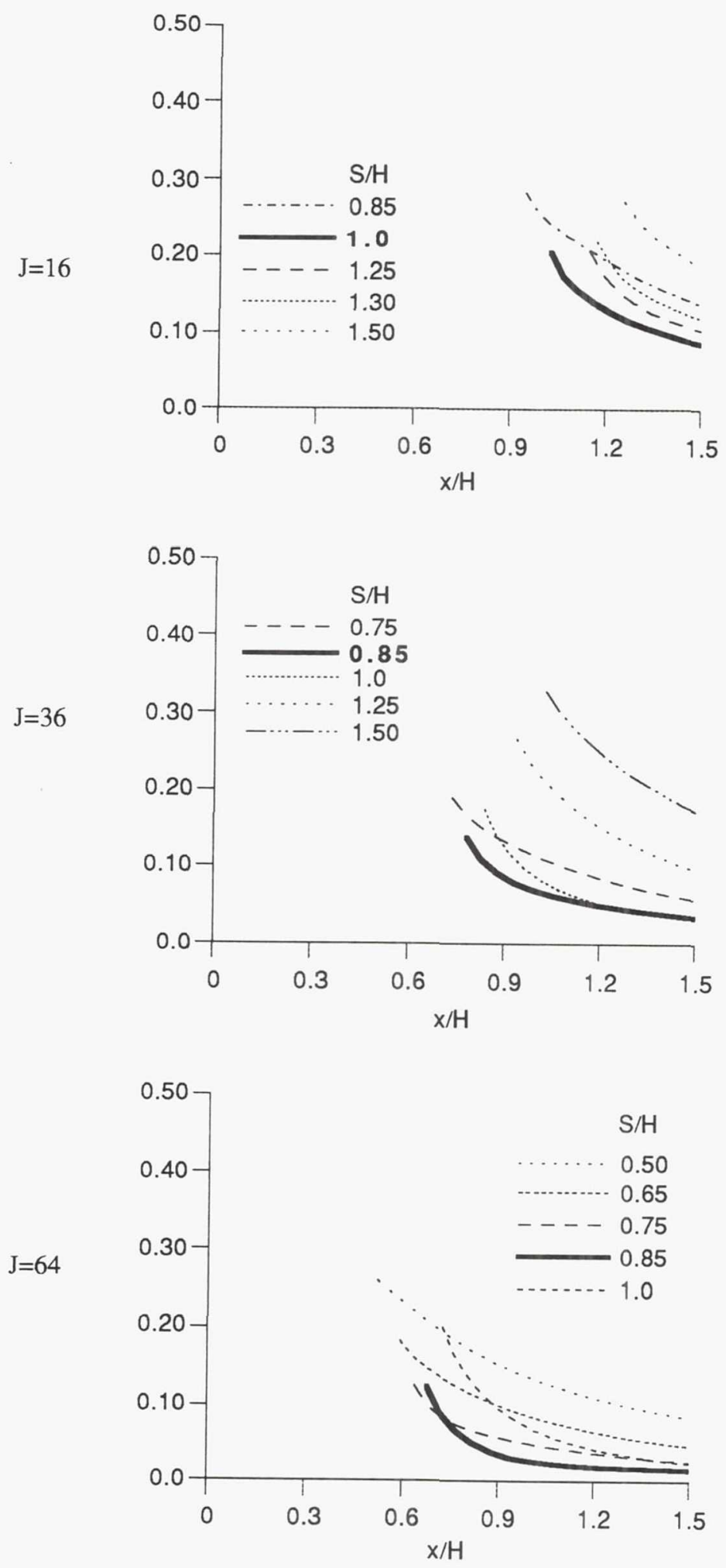

Figure 3. Computational Results of Parametrics 1-6 
Page intentionally left blank 


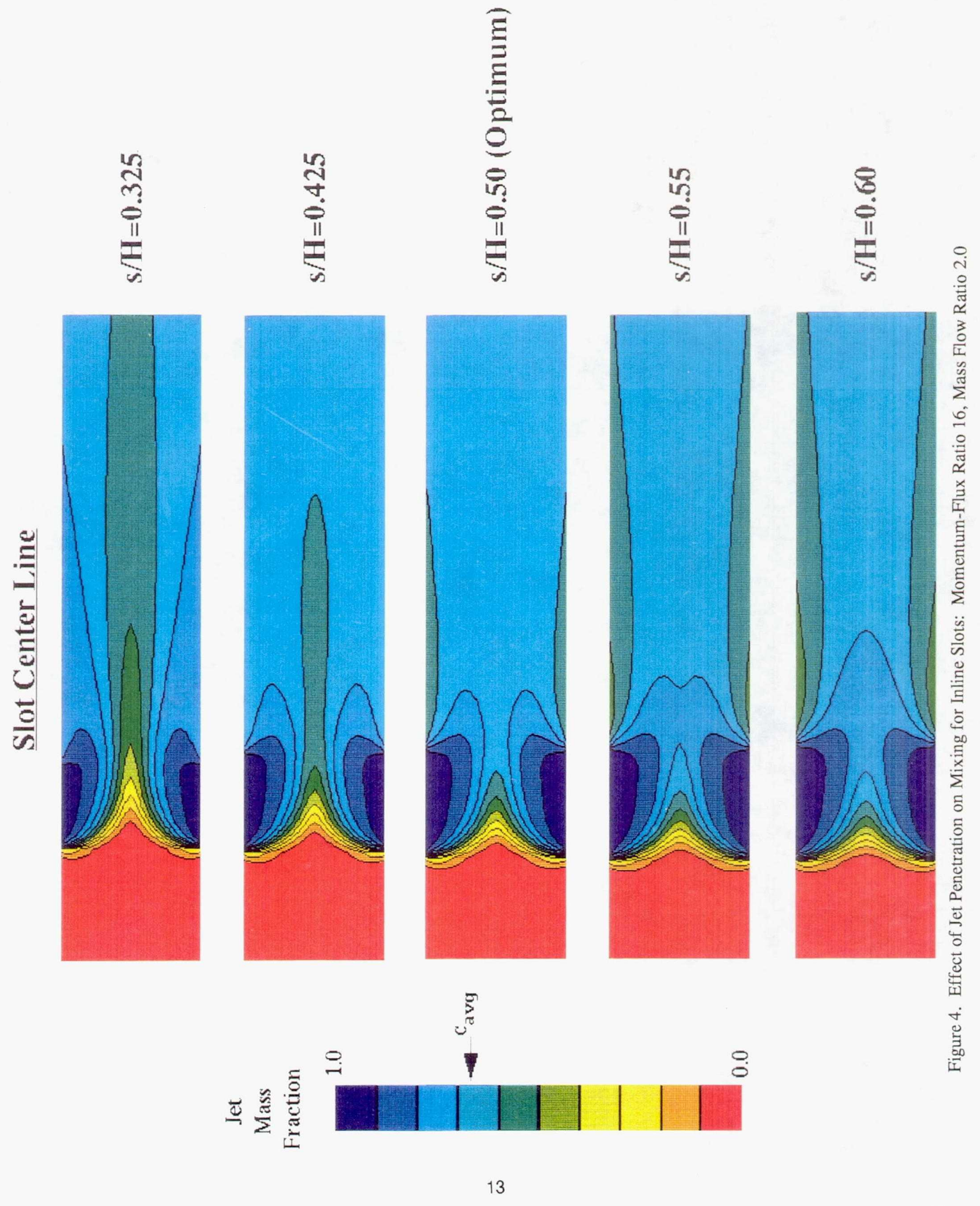


Page intentionally left blank 


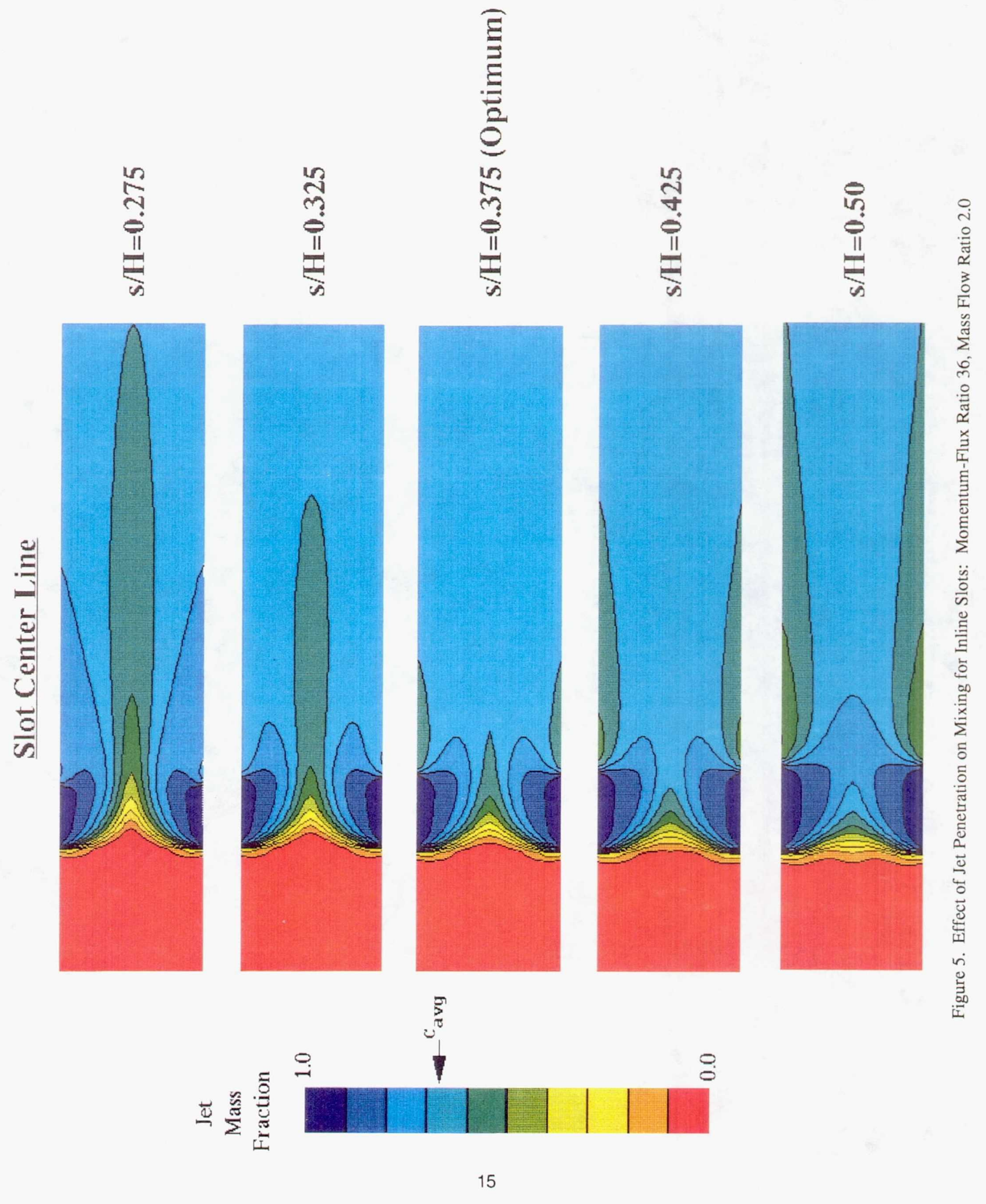


Page intentionally left blank 


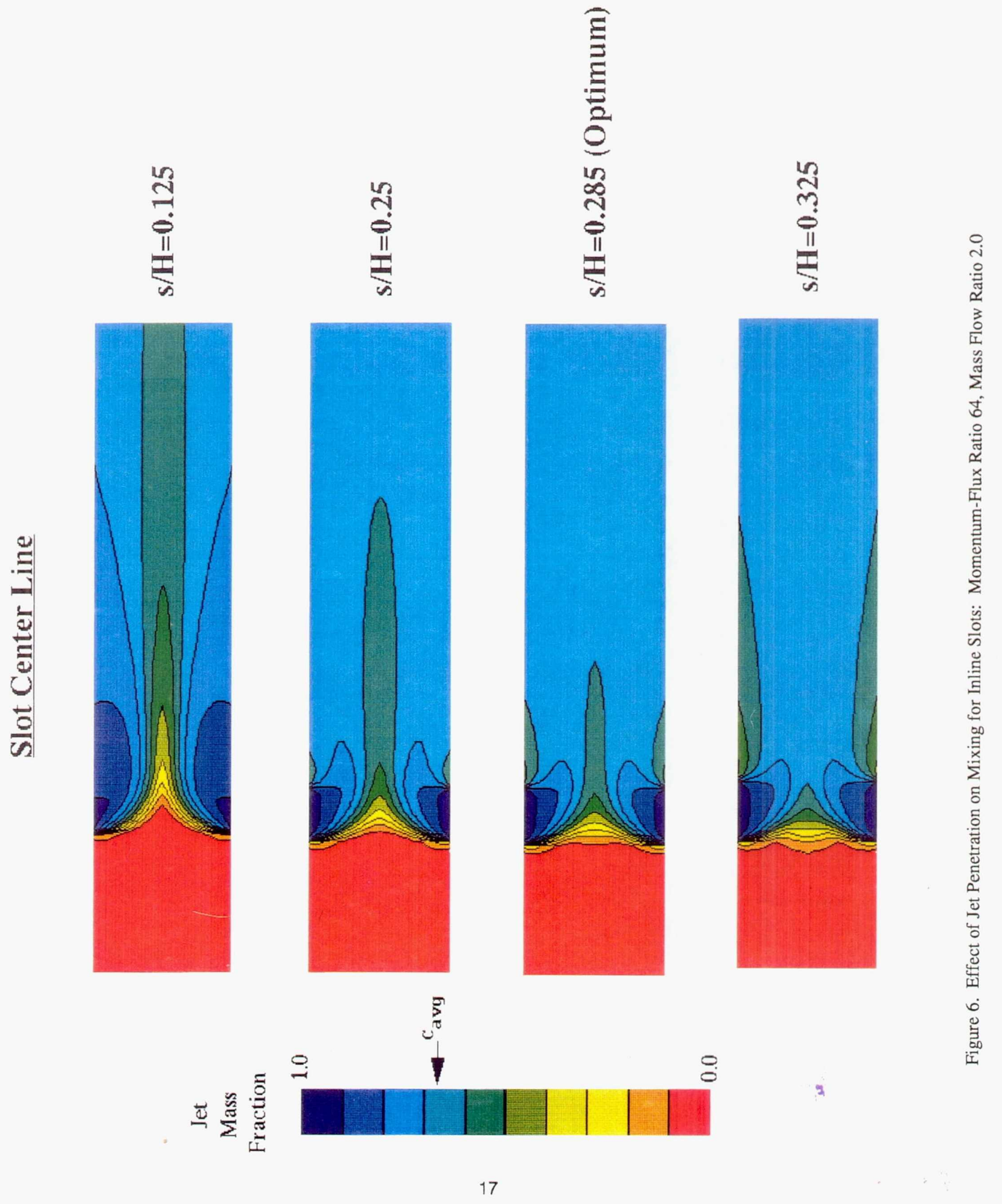


Page intentionally left blank 

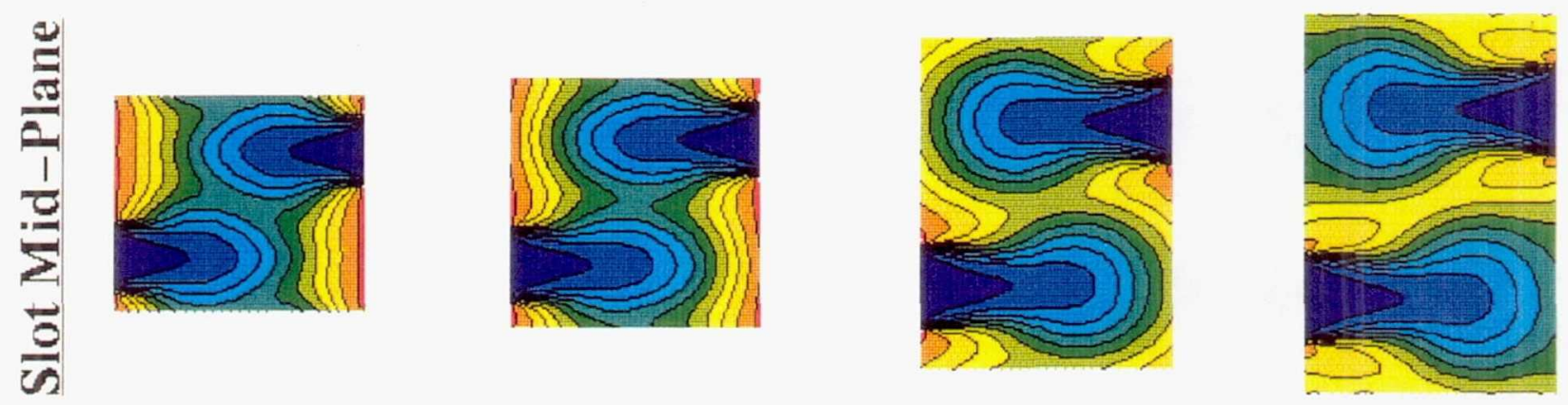

언
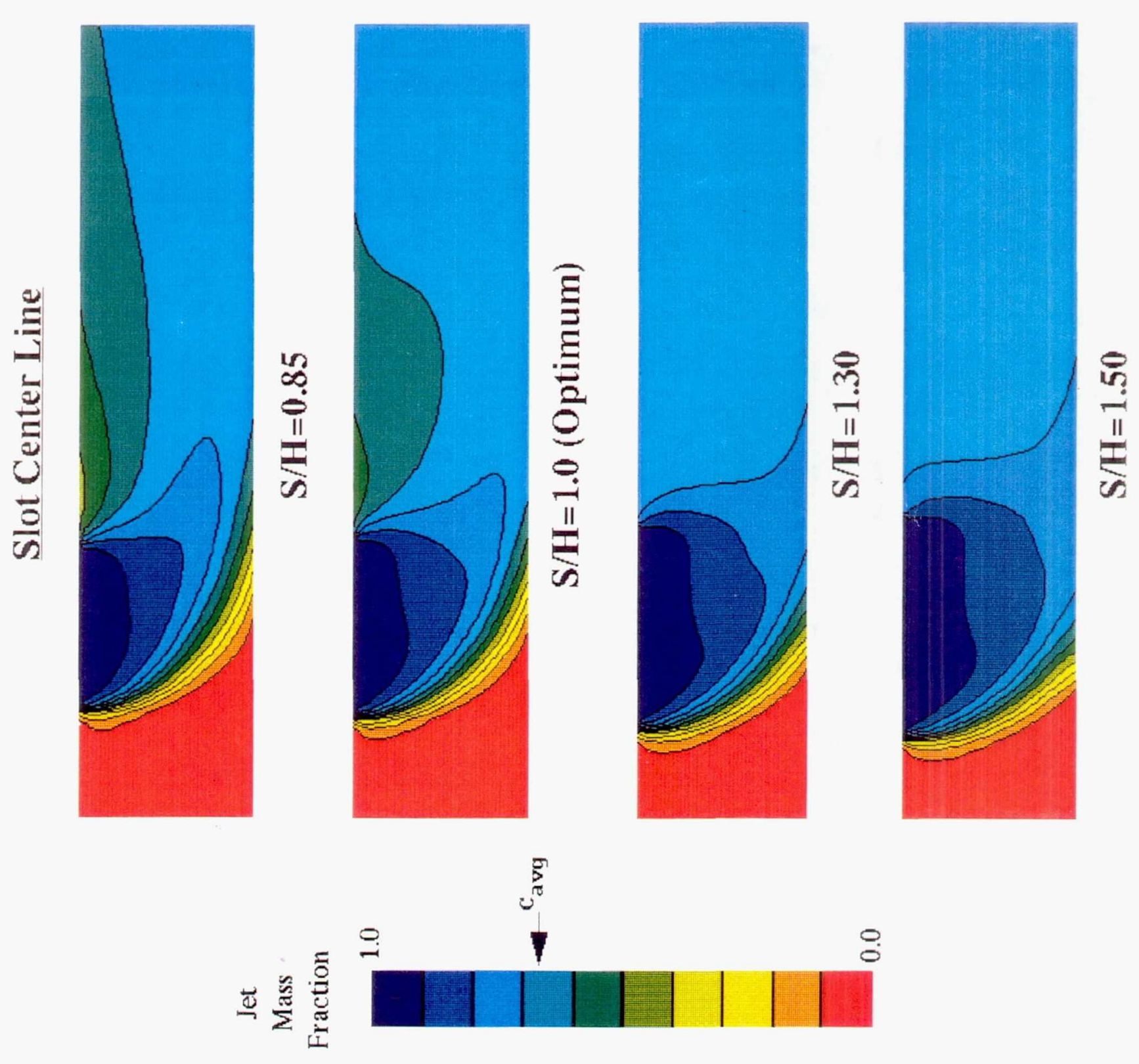

I)

힘ำ 
Page intentionally left blank 

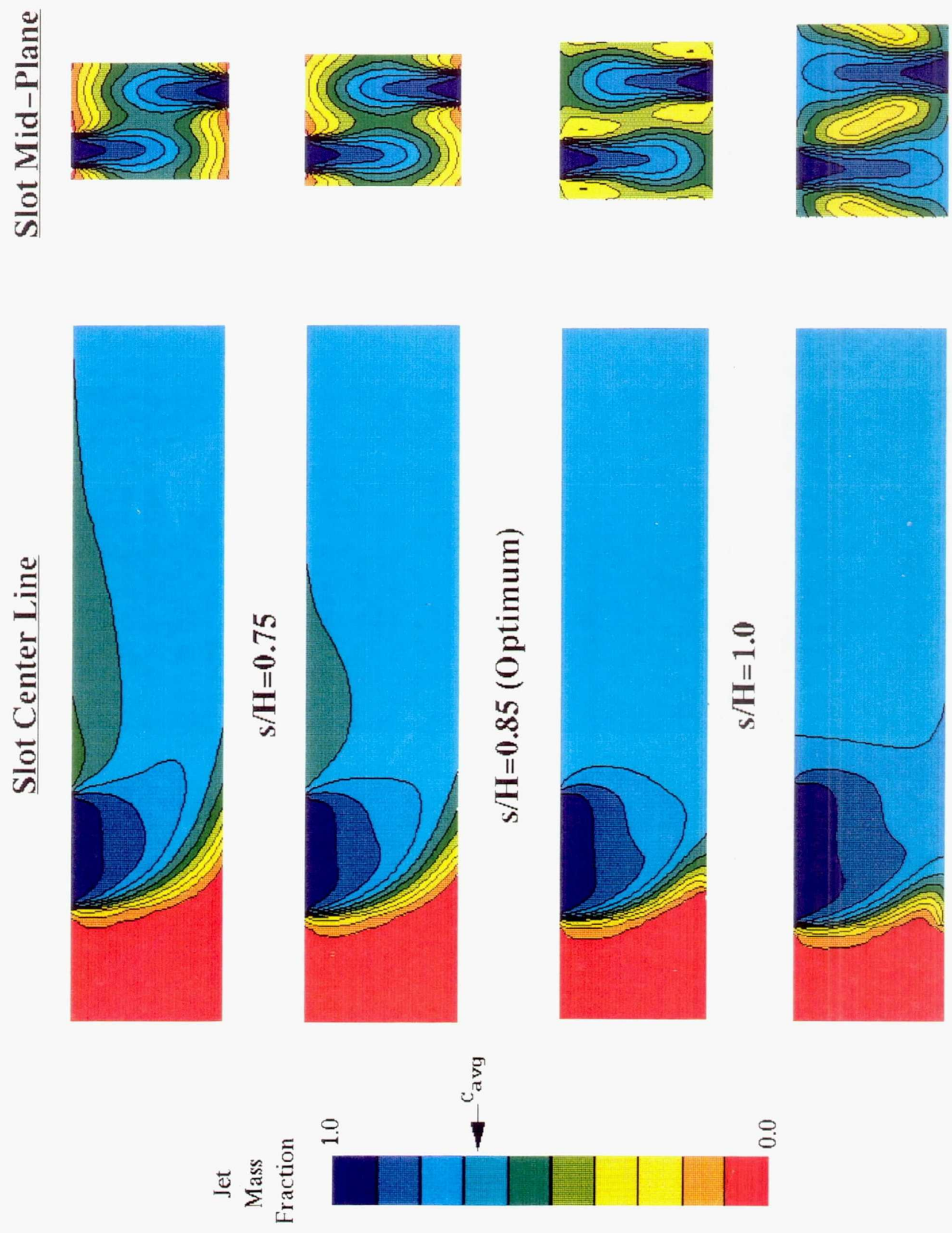

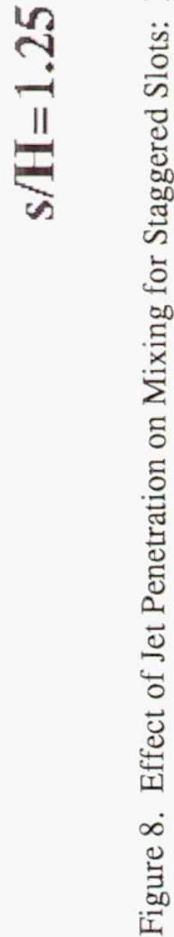


Page intentionally left blank 

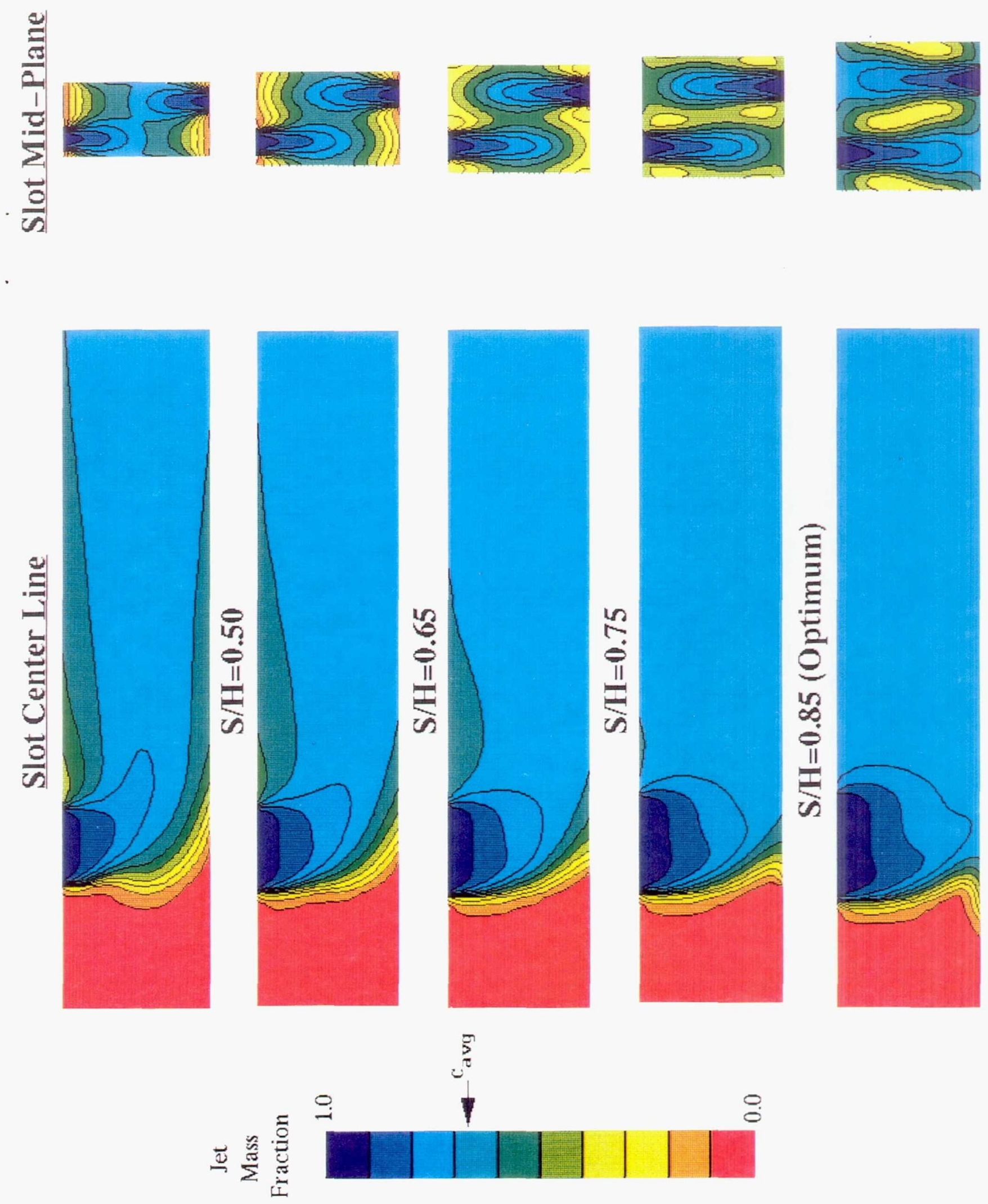

I)

बं 
Page intentionally left blank 


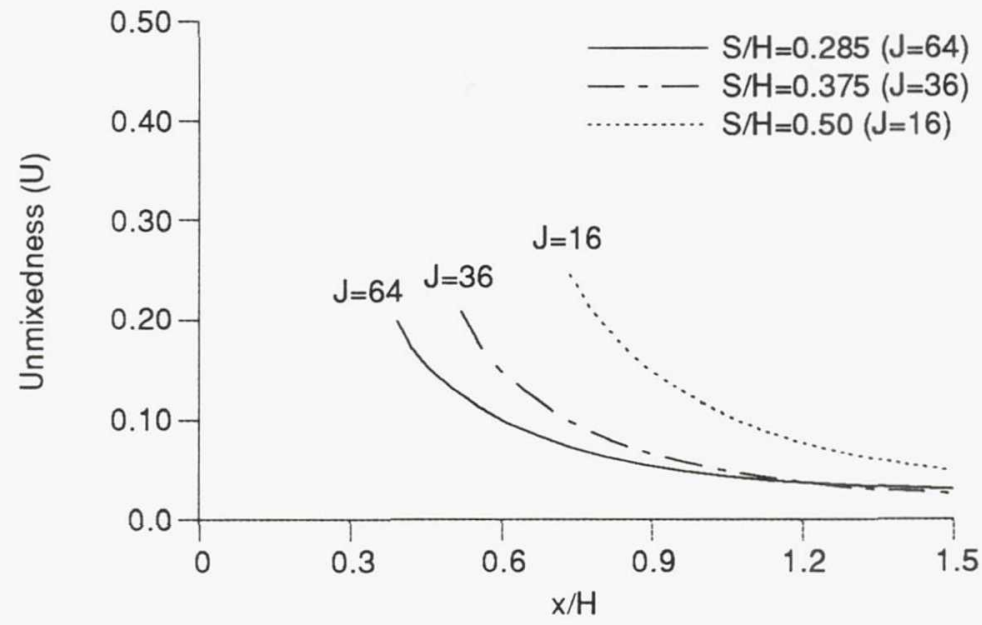

Figure 10. Effect of J on Unmixedness for Inline Slots: Mass Flow Ratio of 2.0

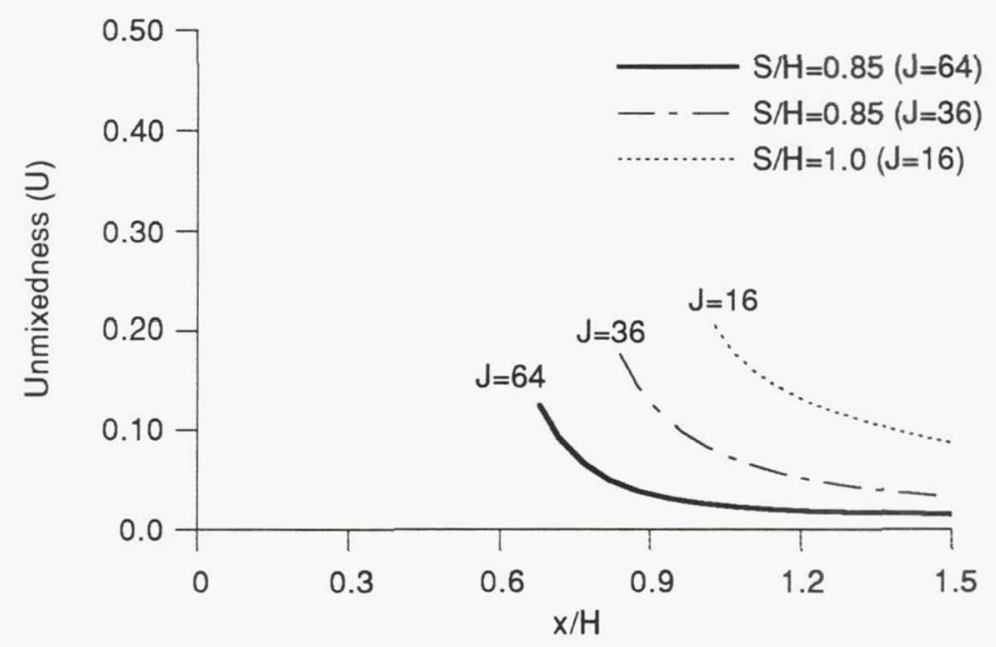

Figure 11. Effect of J on Unmixedness for Staggered Slots: Mass Flow Ratio of 2.0 
Page intentionally left blank 

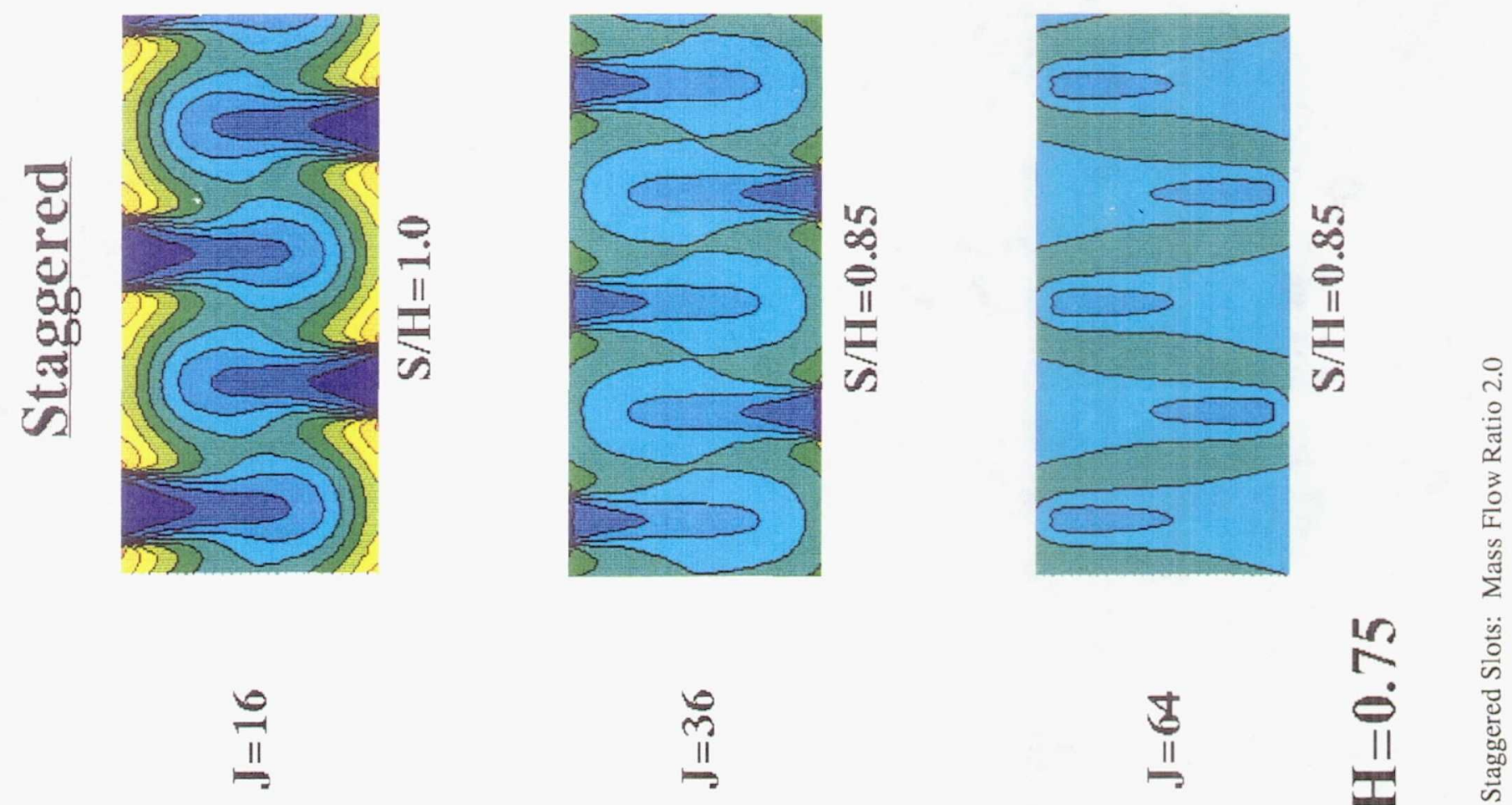

III
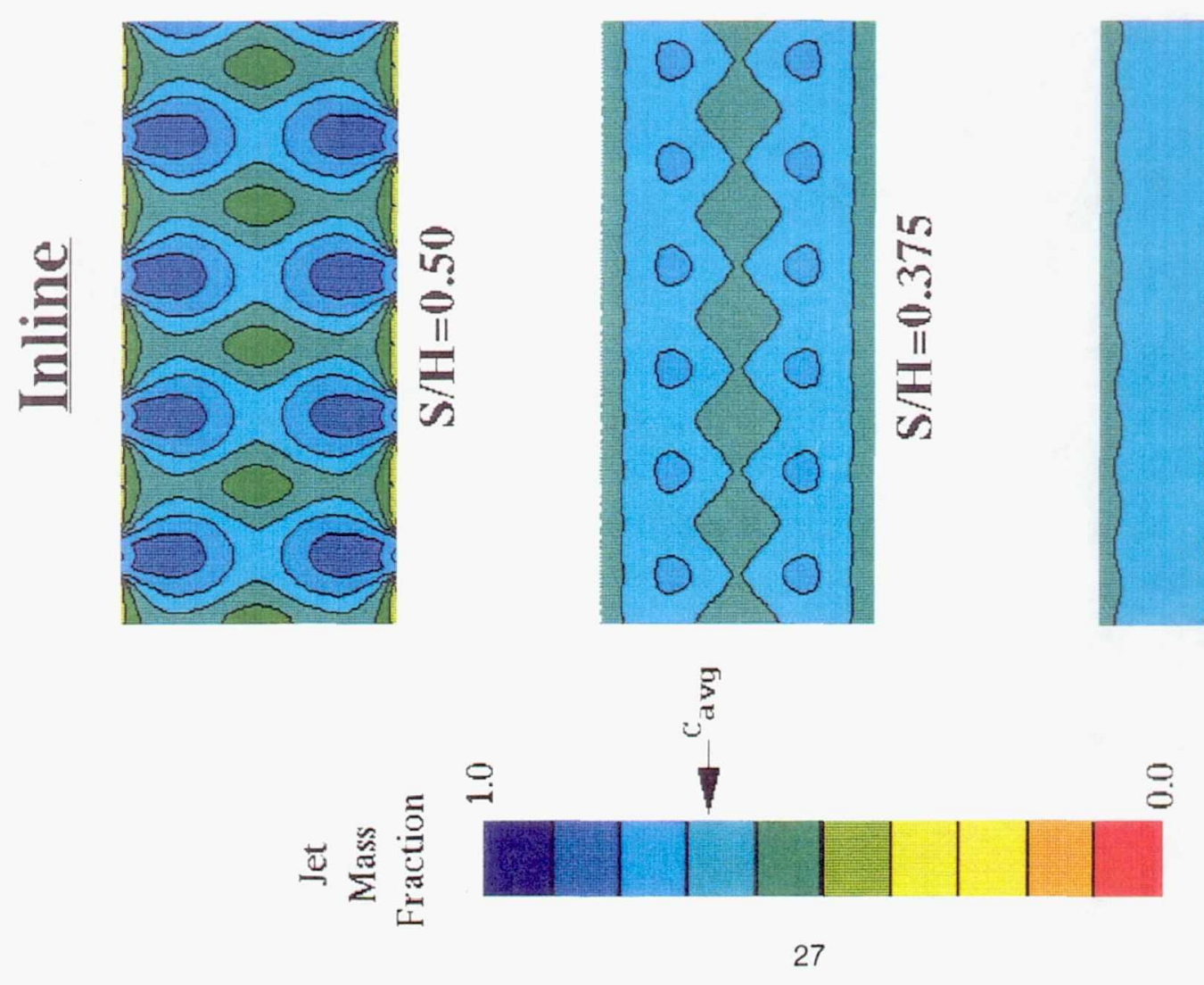
Page intentionally left blank 


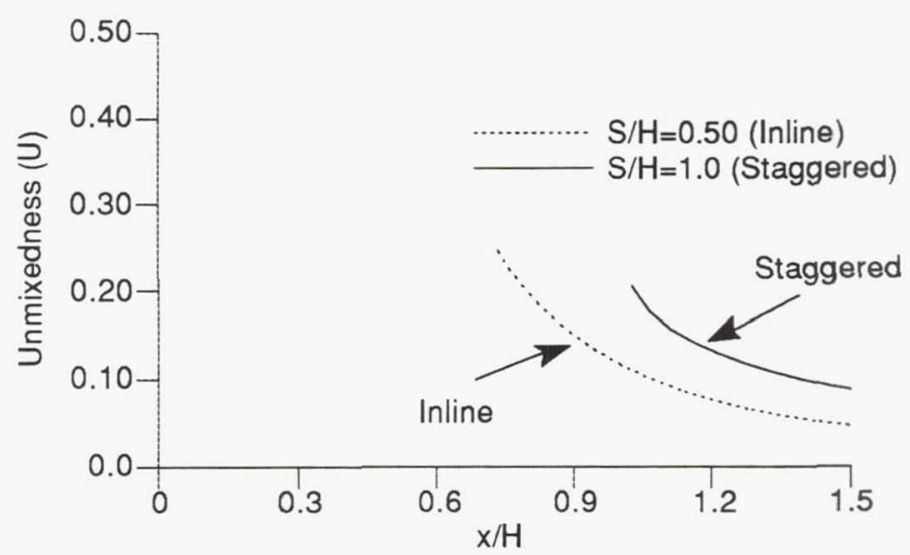

Figure 13. Effect of Lateral Arrangement on Unmixedness, J=16

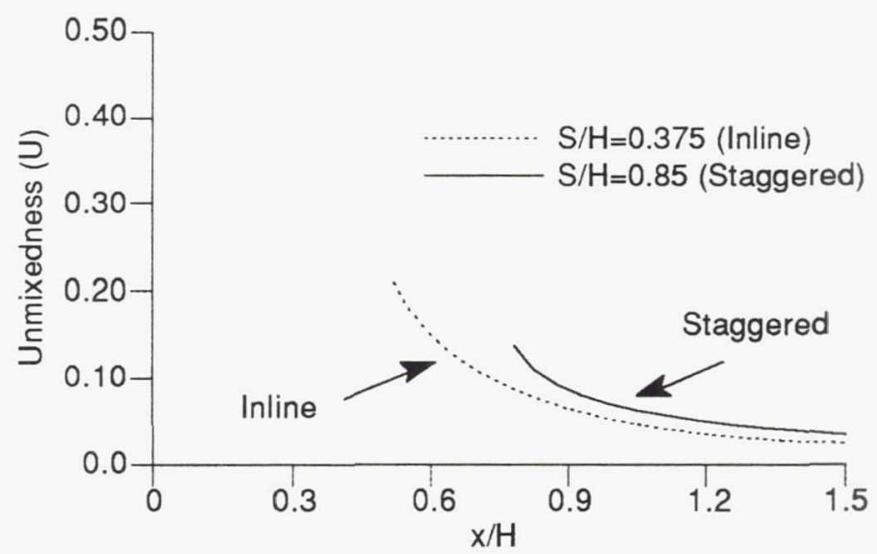

Figure 14. Effect of Lateral Arrangement on Unmixedness, $\mathrm{J}=36$

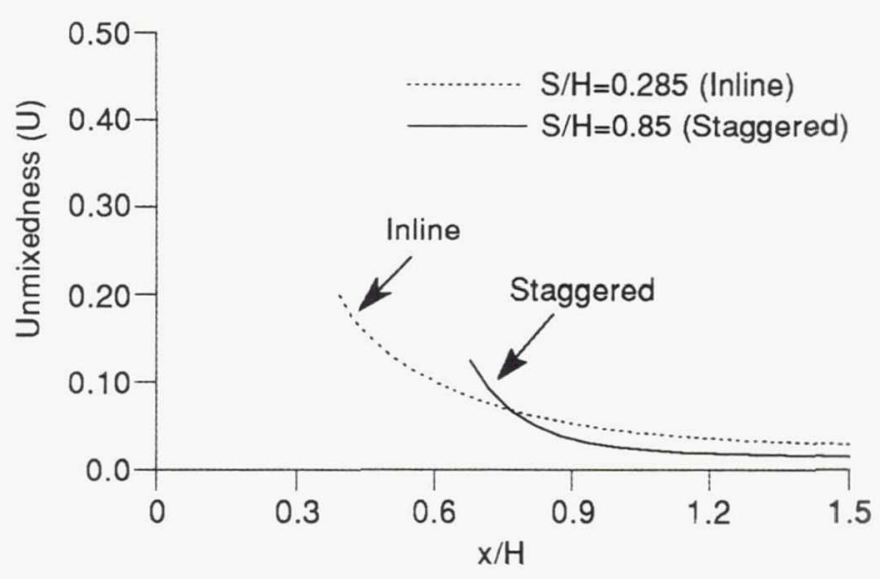

Figure 15. Effect of Lateral Arrangement on Unmixedness, J=64 
Page intentionally left blank 

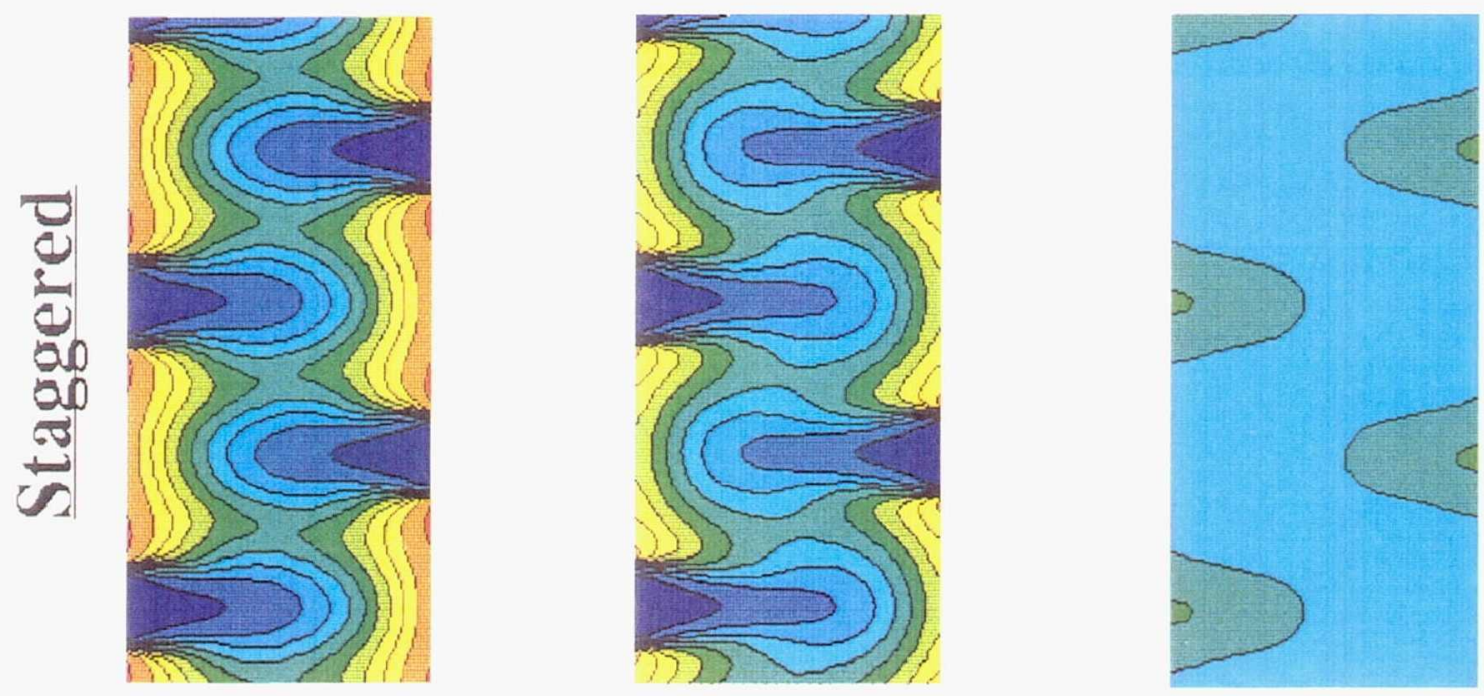

$=$
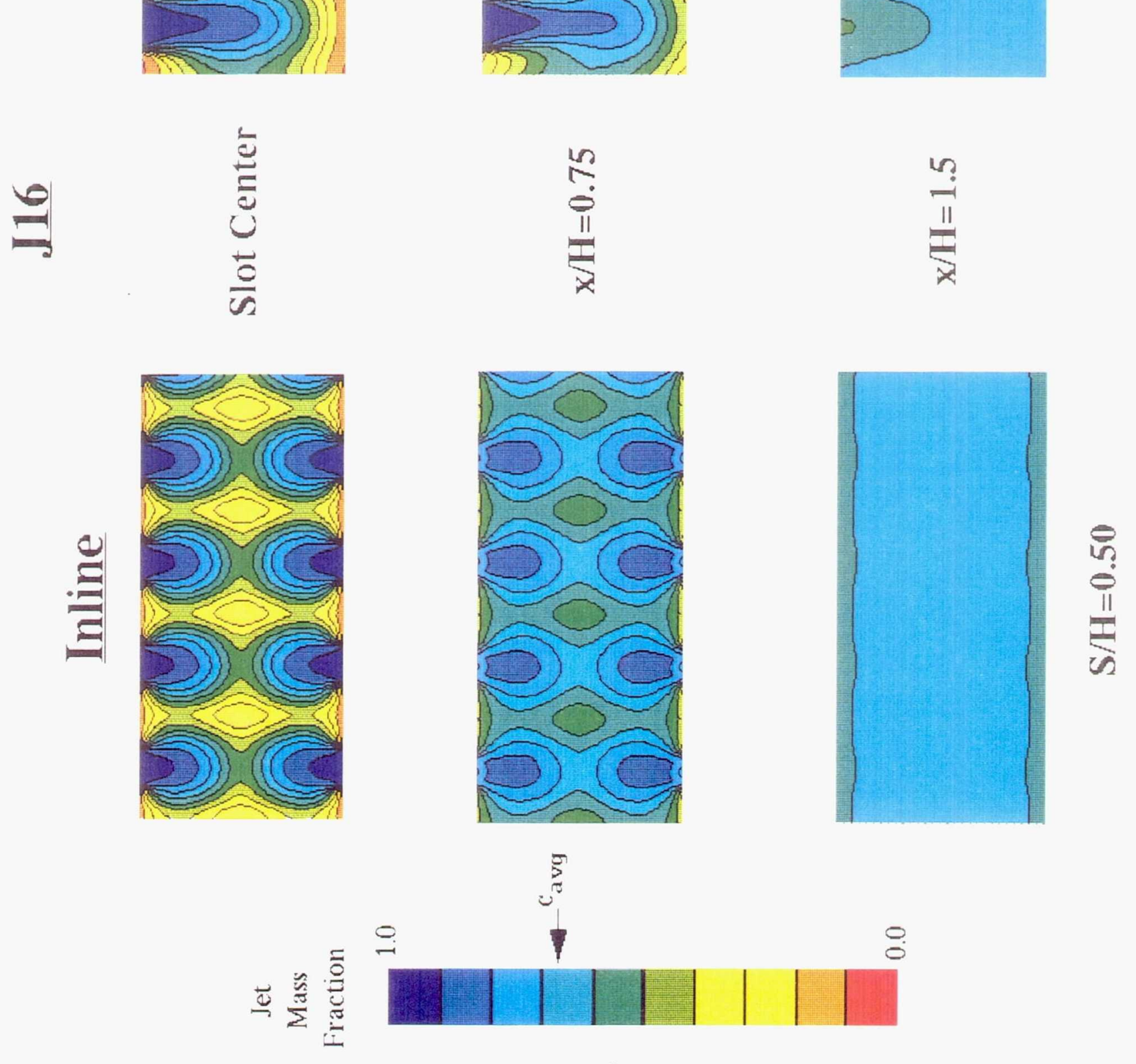
Page intentionally left blank 

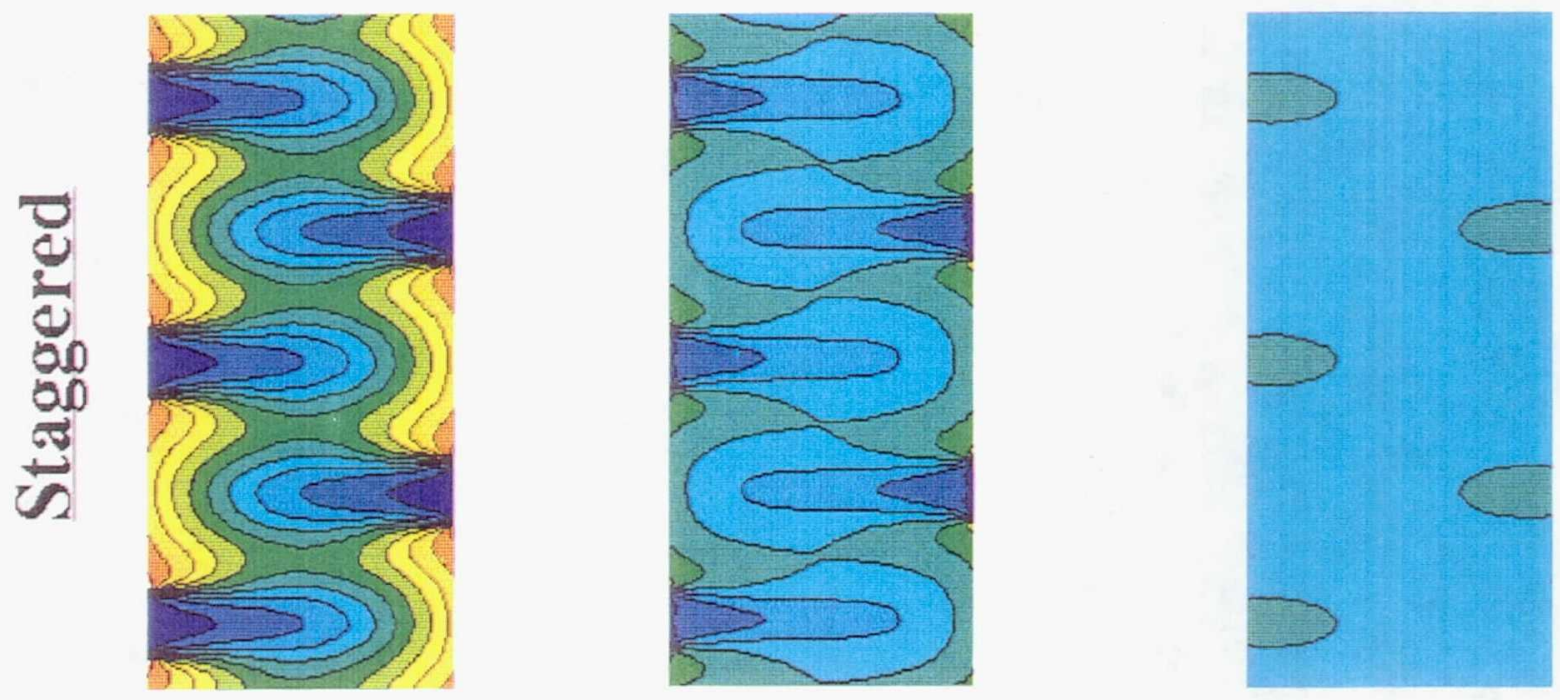

${ }_{0}^{\infty}$
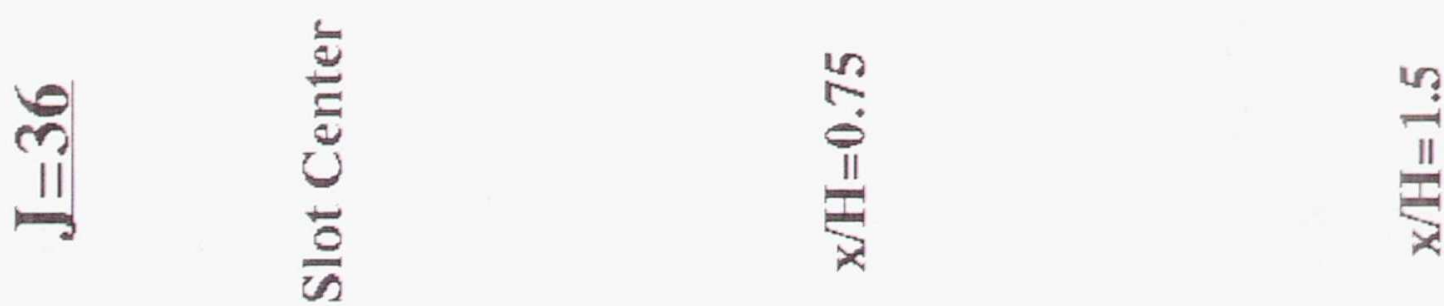

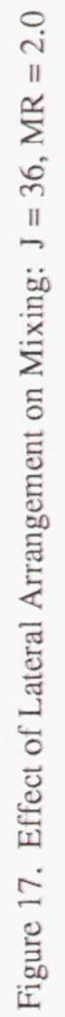
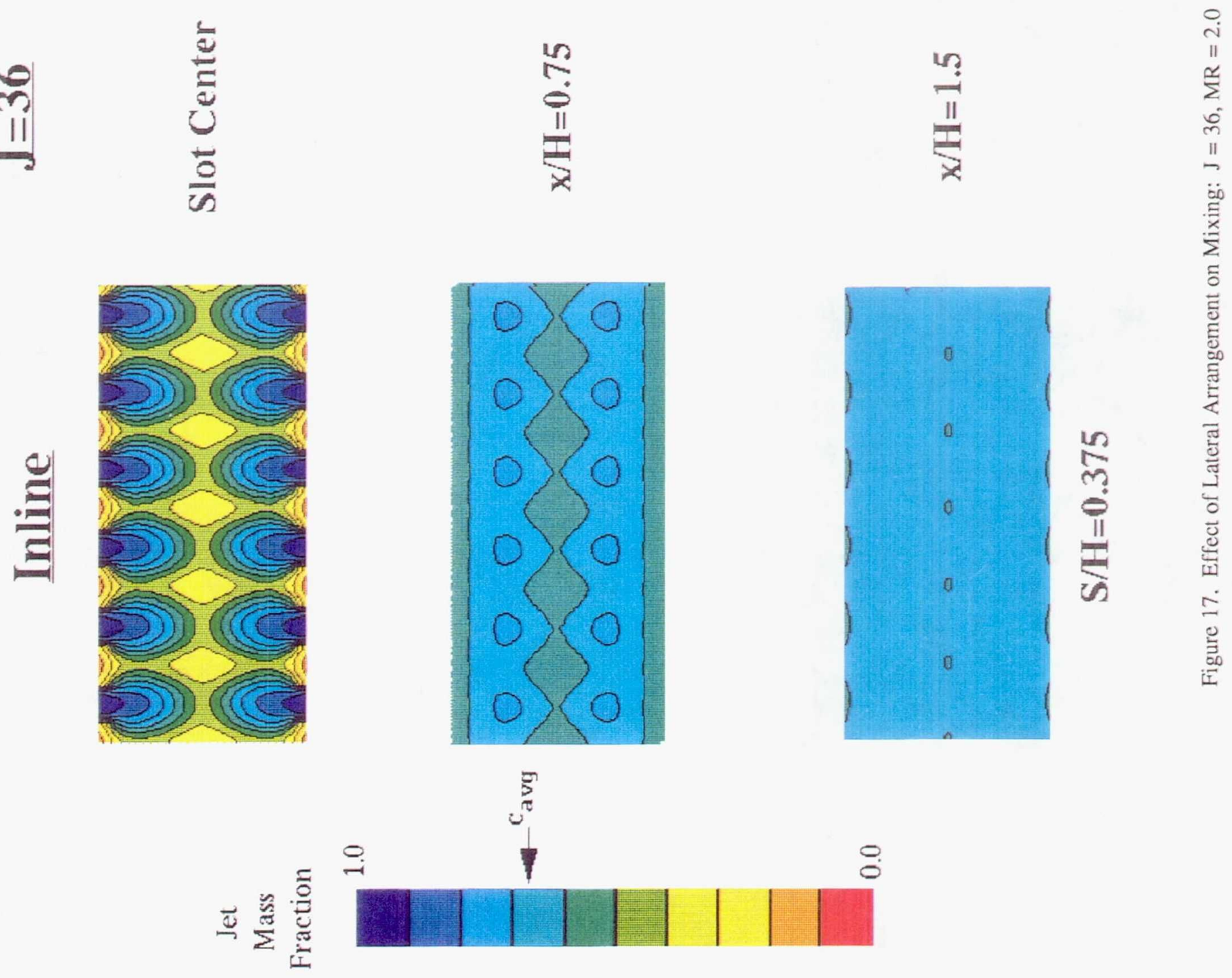
Page intentionally left blank 

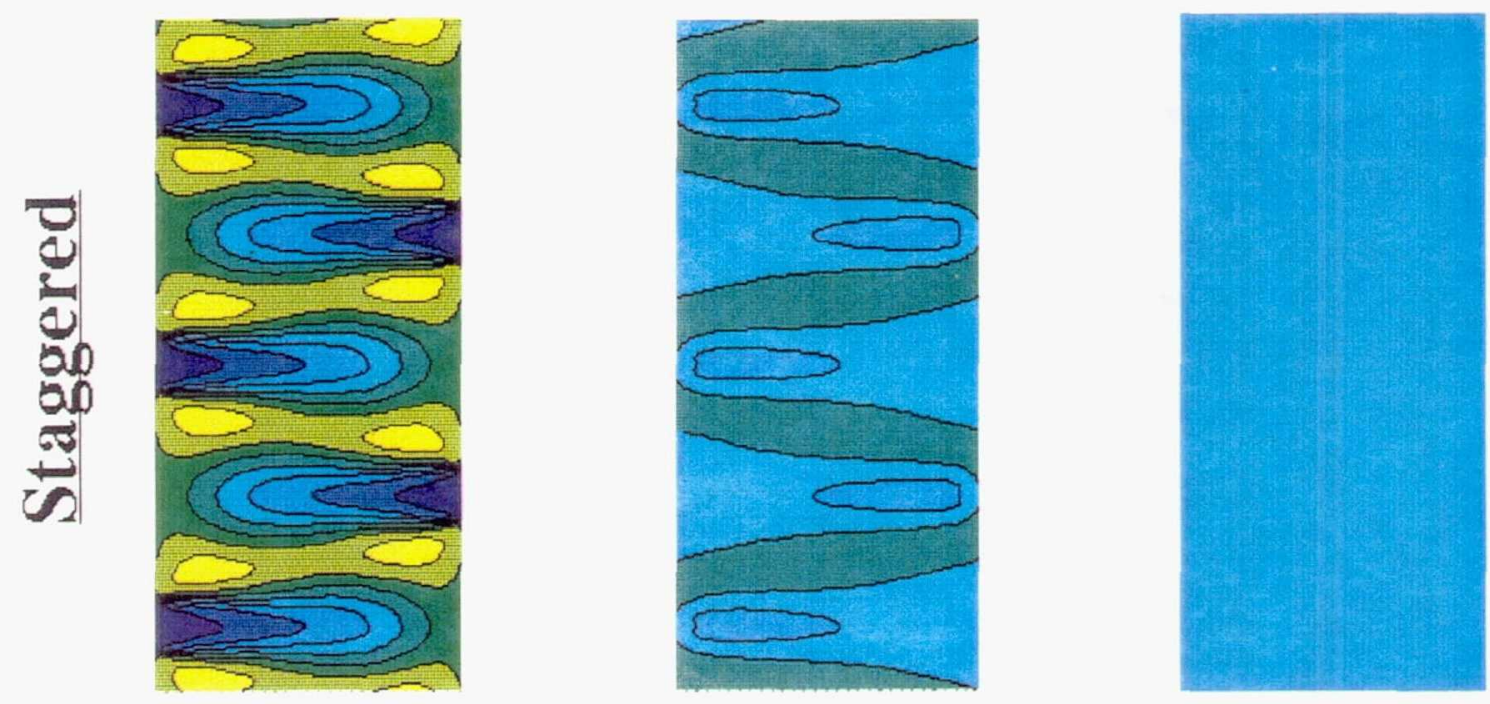

$n$
0
0
0

III
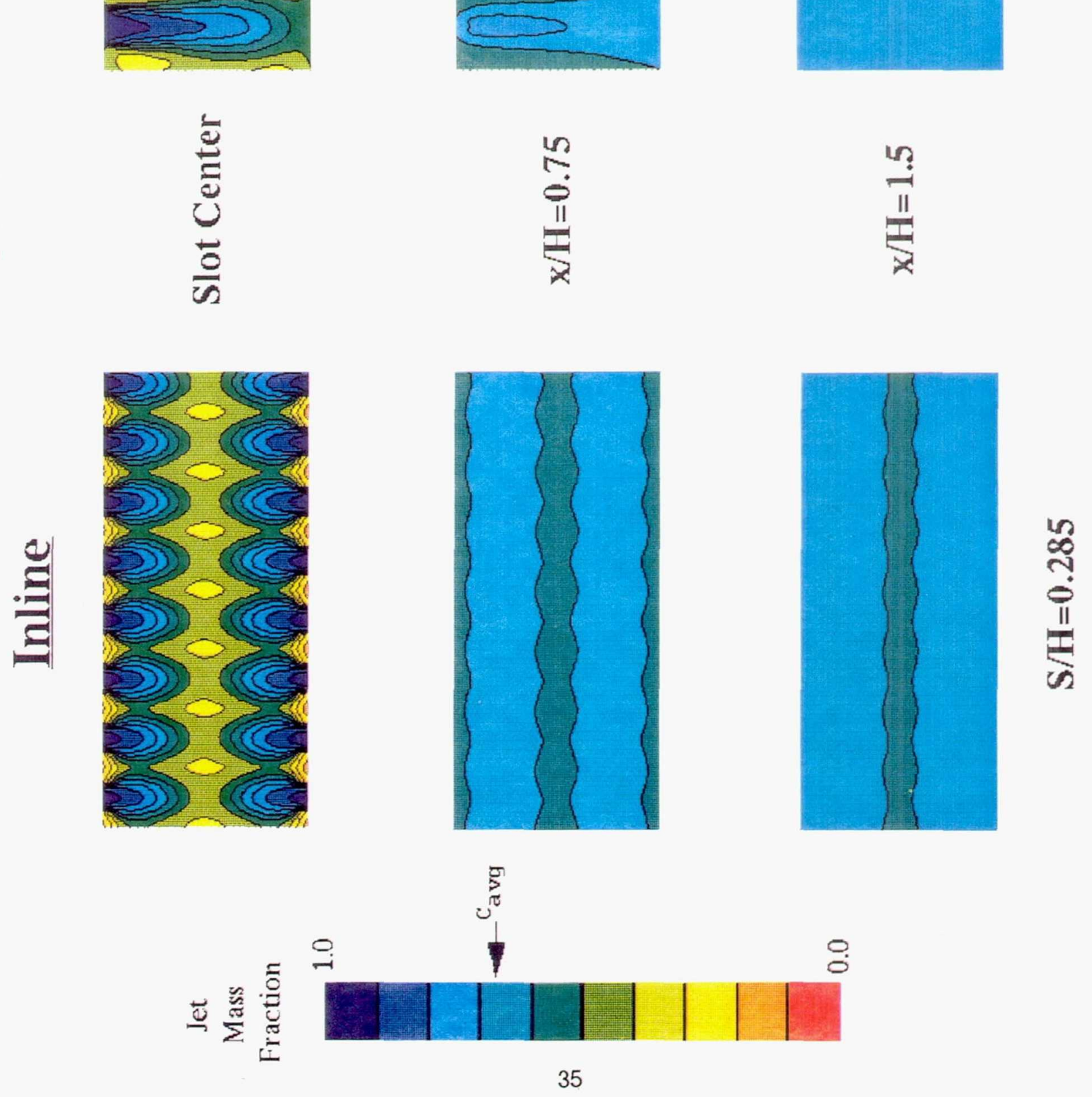
Page intentionally left blank 

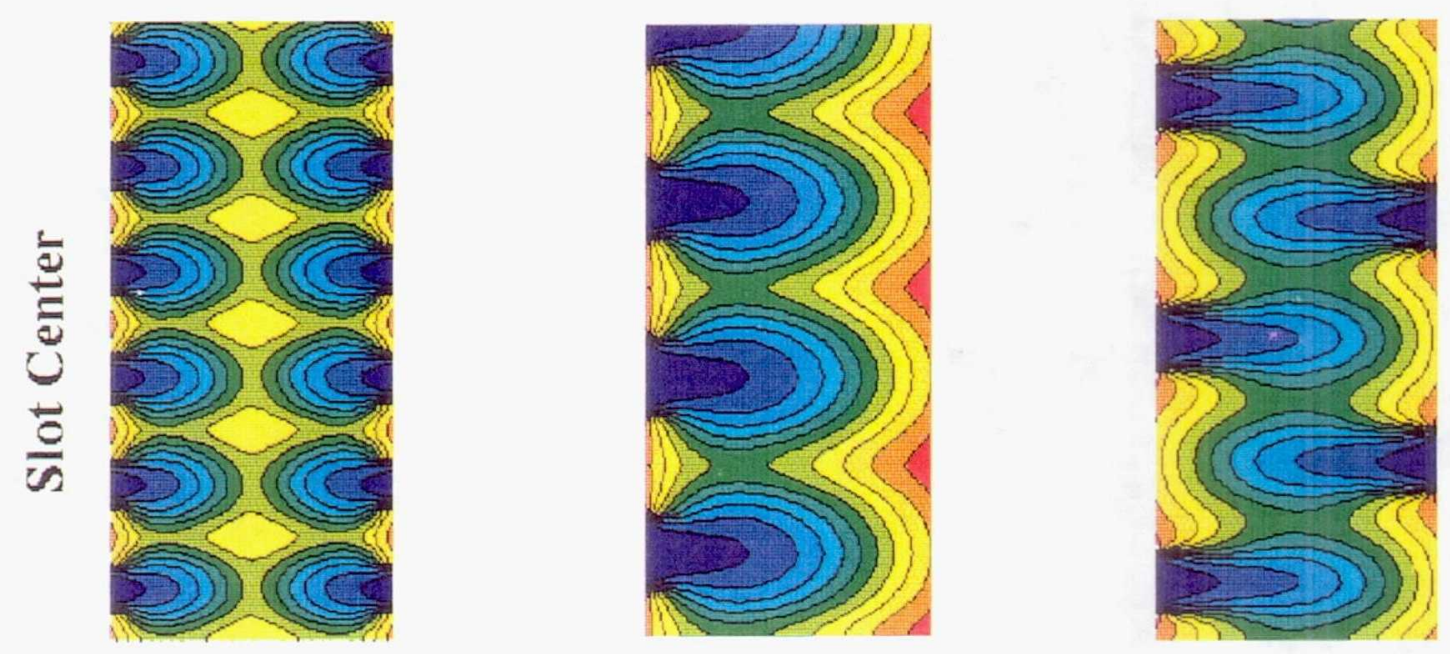

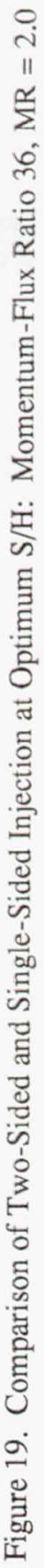
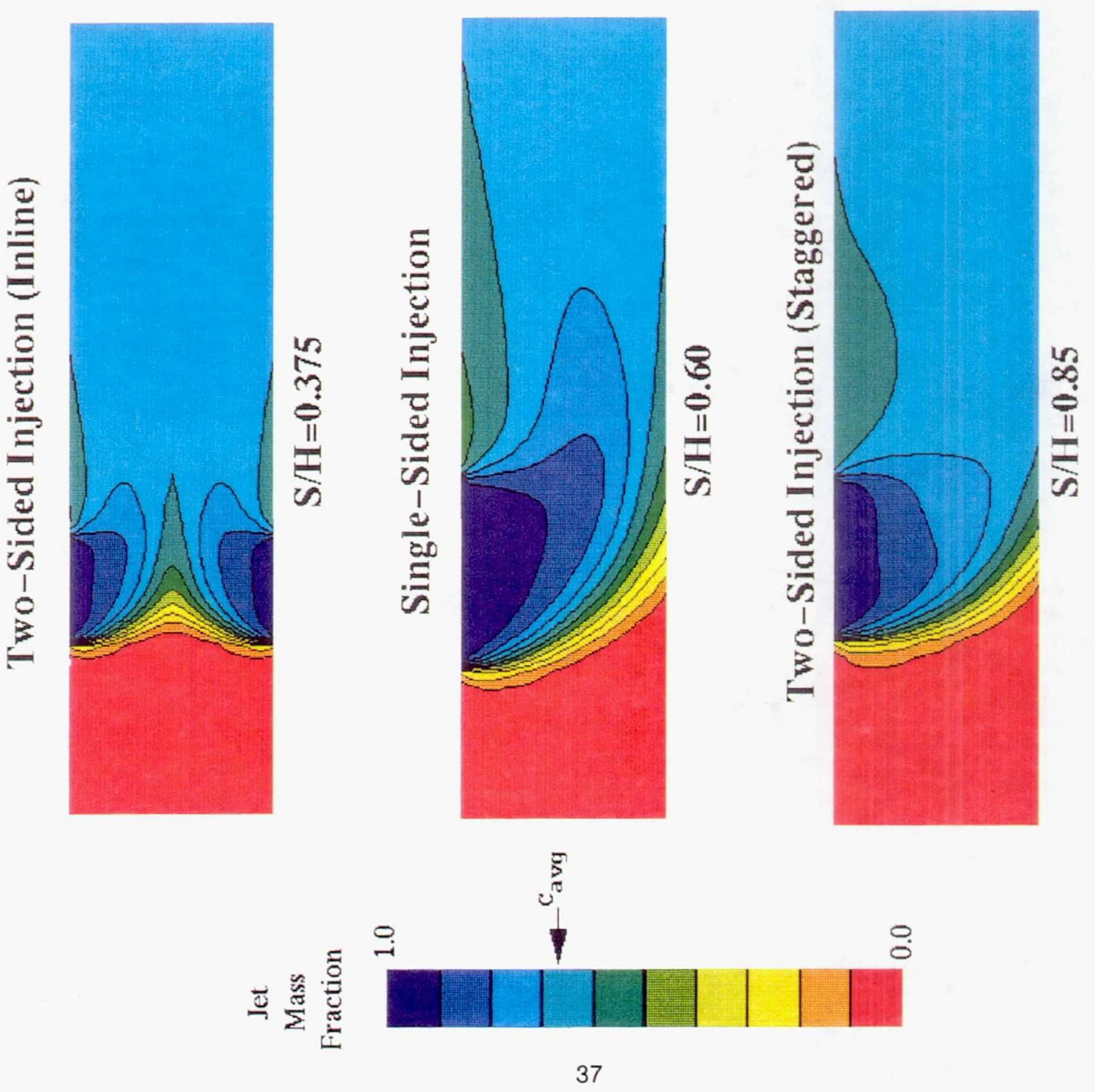
Page intentionally left blank 


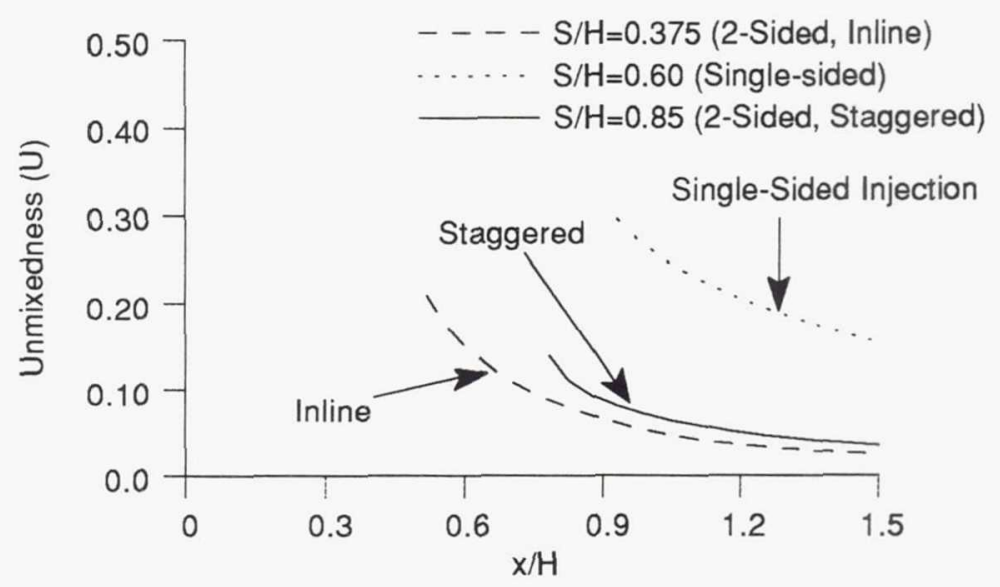

Figure 20. Unmixedness Curves for Two-Sided vs. Single-Sided Injection; Momentum-Flux Ratio 36, Mass Flow Ratio 2.0

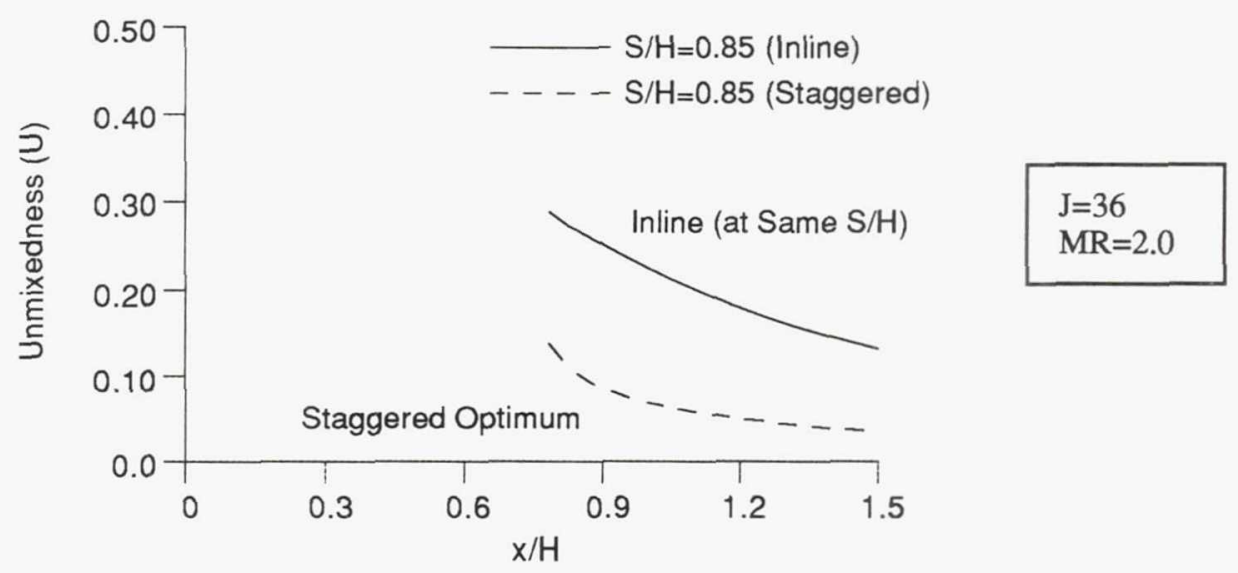

Figure 22. Unmixedness Comparison of Inline and Staggered Configurations at Staggered Optimum S/H

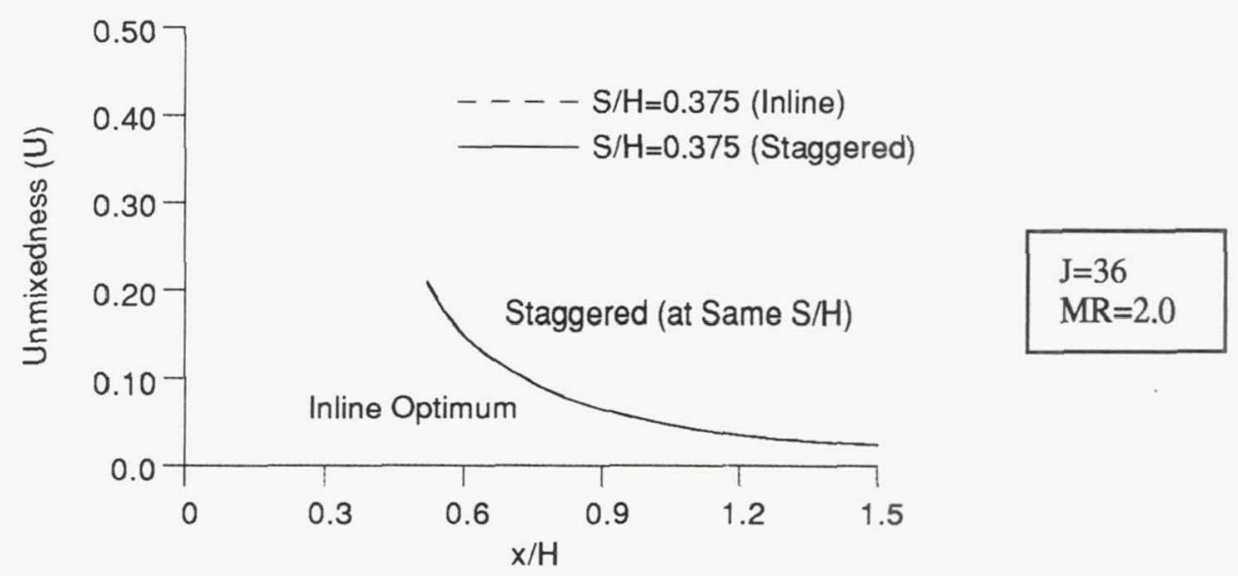

Figure 23. Unmixedness Comparison of Inline and Staggered Configurations at Inline Optimum S/H 
Page intentionally left blank 

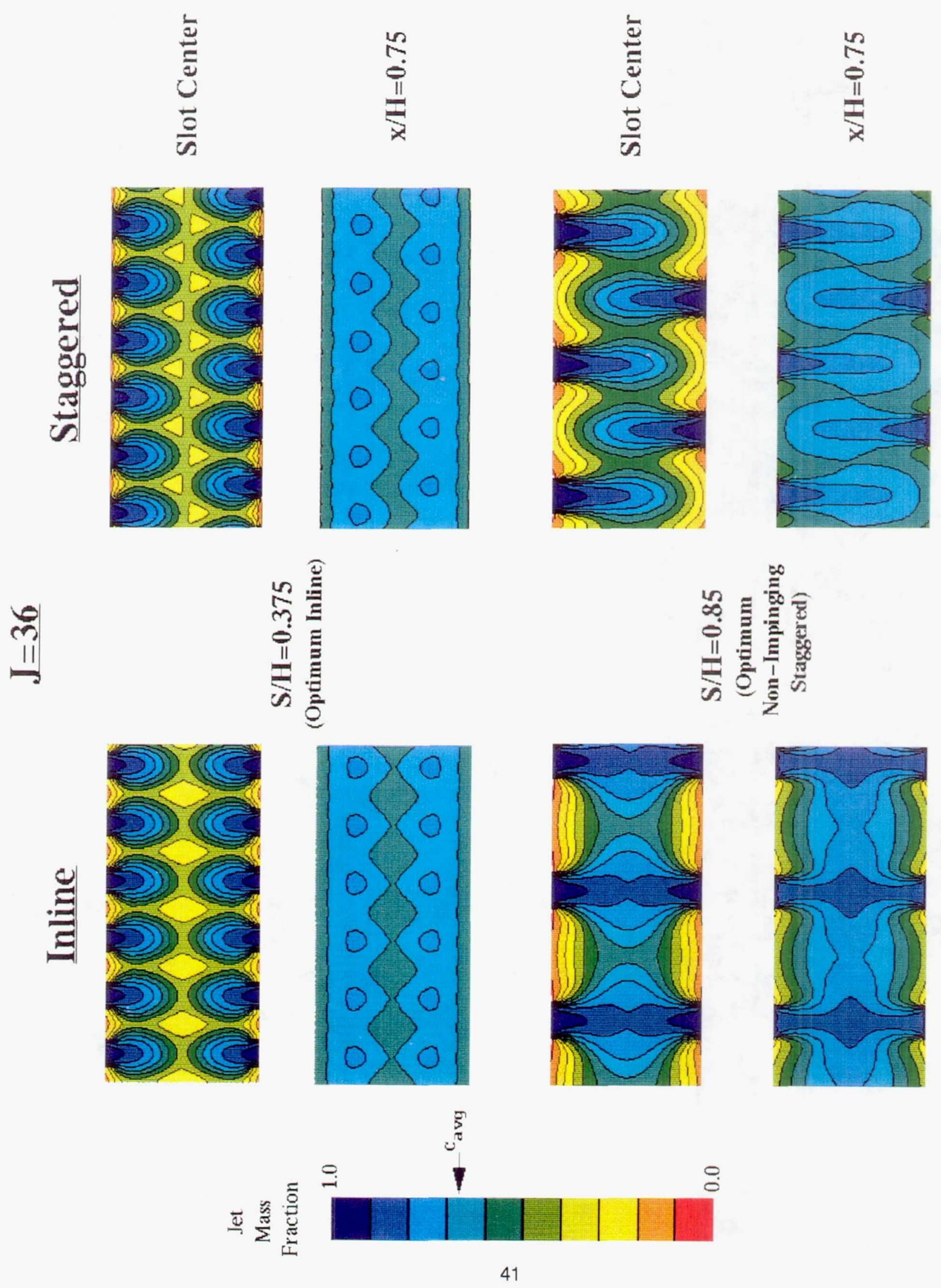
Page intentionally left blank 


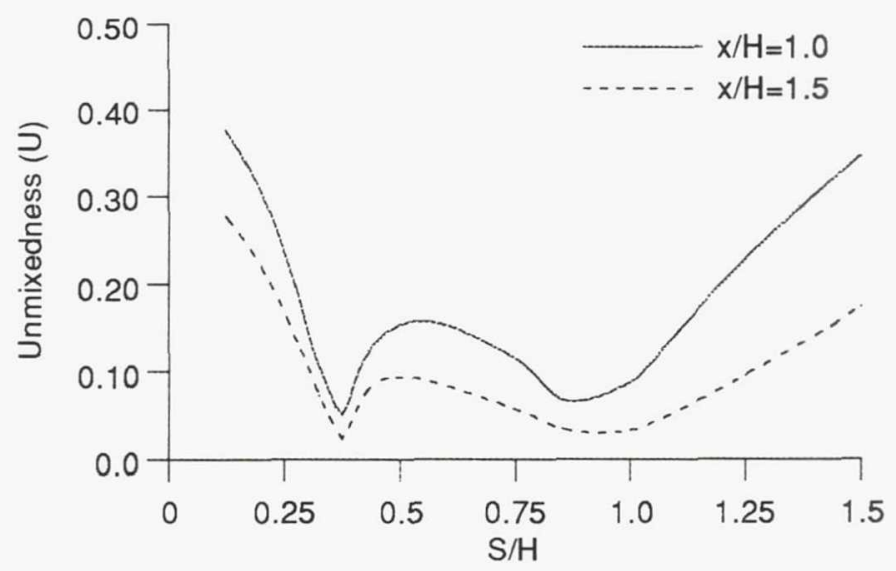

Figure 24. Staggered Cases Produce Double-Valued Function of Unmixedness Versus S/H (Parametric 2, J=36)

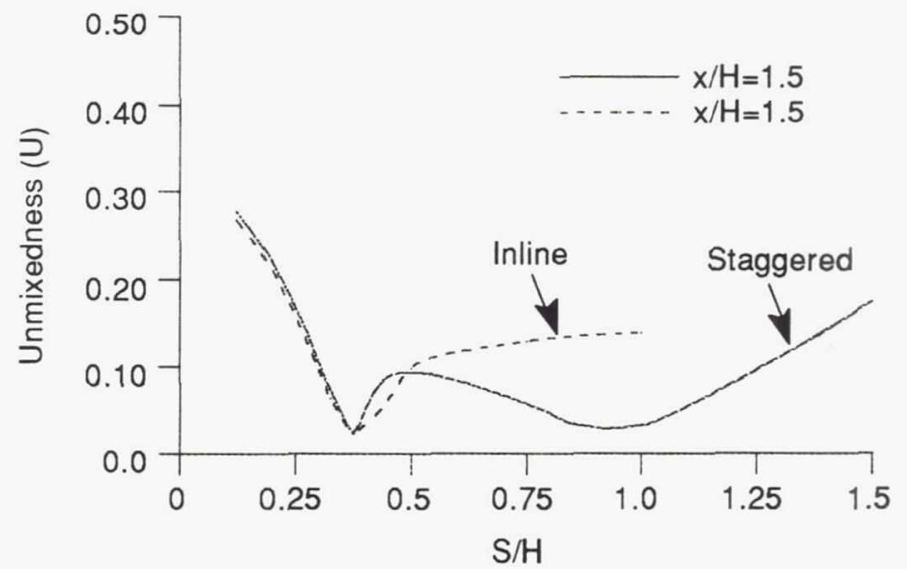

Figure 25. Unmixedness Comparison of Inline and Staggered Slots for $\mathrm{S} / \mathrm{H}$ Variation at $\mathrm{x} / \mathrm{H}=1.5(\mathrm{~J}=36)$

Table 2. Empircal and Numerical Determined Constants at Optimum S/H

\begin{tabular}{|c|c|c|c|c|c|c|c|}
\hline \multirow{2}{*}{ Geometry } & \multirow{2}{*}{$\begin{array}{c}\text { Lateral } \\
\text { Arrangement }\end{array}$} & \multirow{2}{*}{$m_{j} / m_{\infty}$} & \multirow{2}{*}{$J$} & \multirow{2}{*}{$\mathrm{S} / \mathrm{H}$} & \multicolumn{2}{|c|}{$\mathbf{C}=\mathbf{S} / \mathbf{H} \cdot \sqrt{ } \mathbf{J}$} & \multirow{2}{*}{ Blockage } \\
\hline & & & & & Empirical & Numerical & \\
\hline \multirow[t]{3}{*}{ Two-Sided } & Inline & 2.0 & 16 & 0.50 & 1.25 & 2.0 & $35 \%$ \\
\hline & Inline & & 36 & 0.375 & & 2.25 & $33 \%$ \\
\hline & Inline & & 64 & 0.285 & 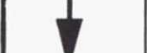 & 2.28 & $33 \%$ \\
\hline & Staggered & & 16 & 1.0 & 5.0 & 4.0 & $25 \%$ \\
\hline & Staggered & & 36 & 0.85 & & 5.1 & $22 \%$ \\
\hline & Staggered & & 64 & 0.85 & 1 & 6.8 & $19 \%$ \\
\hline Single-Sided & & & 36 & 0.60 & 2.5 & 3.6 & $37 \%$ \\
\hline
\end{tabular}




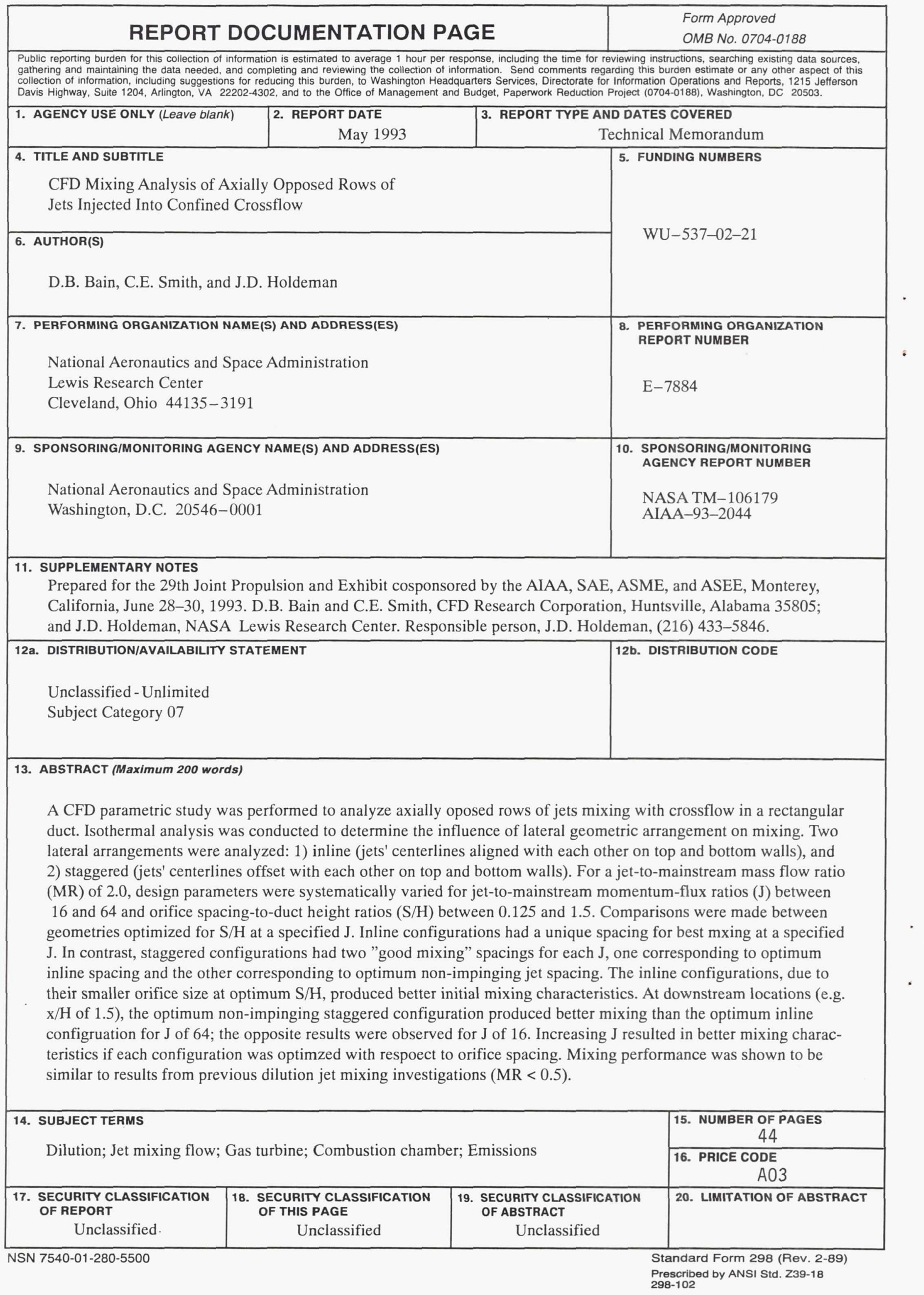

